Florida International University

FIU Digital Commons

$11-4-2019$

\title{
Swiping Right and Sexually Transmitted Diseases (STD): \\ Examining Venue Selection, Risky Sexual Behaviors, and STD among Persons Living with HIV, Florida, 2014-2017
}

Isabel S. Griffin

Florida International University, igrif005@fiu.edu

Follow this and additional works at: https://digitalcommons.fiu.edu/etd

Part of the Epidemiology Commons

\section{Recommended Citation}

Griffin, Isabel S., "Swiping Right and Sexually Transmitted Diseases (STD): Examining Venue Selection, Risky Sexual Behaviors, and STD among Persons Living with HIV, Florida, 2014-2017" (2019). FIU Electronic Theses and Dissertations. 4302.

https://digitalcommons.fiu.edu/etd/4302

This work is brought to you for free and open access by the University Graduate School at FIU Digital Commons. It has been accepted for inclusion in FIU Electronic Theses and Dissertations by an authorized administrator of FIU Digital Commons. For more information, please contact dcc@fiu.edu. 


\section{FLORIDA INTERNATIONAL UNIVERSITY}

Miami, Florida

\section{SWIPING RIGHT AND SEXUALLY TRANSMITTED DISEASES (STD): \\ EXAMINING VENUE SELECTION, RISKY SEXUAL BEHAVIORS, AND STD \\ AMONG PERSONS LIVING WITH HIV, FLORIDA, 2014-2017}

A dissertation submitted in partial fulfillment of the

requirements for the degree of

DOCTOR OF PHILOSOPHY

in

PUBLIC HEALTH

by

Isabel Griffin

2019 
To: Dean Tomás R. Guilarte

Robert Stempel College of Public Health and Social Work

This dissertation, written by Isabel Griffin, and entitled Swiping Right and Sexually

Transmitted Diseases (STD): Examining Venue Selection, Risky Sexual Behaviors, and STD among Persons Living with HIV, Florida, 2014-2017, having been approved in respect to style and intellectual content, is referred to you for judgment.

We have read this dissertation and recommend that it be approved.

$\begin{array}{r}\hline \text { Robert Cook } \\ \hline \text { Kristopher Fennie } \\ \hline \text { Changwon Yoo } \\ \hline \text { Dionne Stephens }\end{array}$

Date of Defense: November 4, 2019

Gladys E. Ibanez, Major Professor

The dissertation of Isabel Griffin is approved.

Dean Tomás R. Guilarte Robert Stempel College of Public Health and Social Work

Andrés G. Gil

Vice President for Research and Economic Development and Dean of the University Graduate School

Florida International University, 2019 
(C) Copyright 2019 by Isabel Griffin

All rights reserved 


\section{DEDICATION}

This dissertation is dedicated to Danielle Fernandez who taught me SAS (and

deserves an honorary $\mathrm{PhD}$ ) and to $\mathrm{Dr}$. Zhang, my boss, who really didn't give me a choice about pursuing a $\mathrm{PhD}$. 


\section{ACKNOWLEDGMENTS}

I thank my major professor, Dr. Ibanez, for her patience, support, continual encouragement, and critical feedback towards ensuring the success of this dissertation. I am also grateful for the critical feedback from Drs. Fennie, Cook, Yoo, and Stephens. I am also appreciative for the support from my cohort, $\mathrm{PhD}$ students, and faculty in the Department of Epidemiology.

The Florida Cohort Study received funding from the National Institite on Alchol Abuse and Alcholism (NIAAA) who funded the collection of data use for this collection of studies. The content is solely the responsibility of the authors and does not represent the views of Florida International University. 


\begin{abstract}
OF THE DISSERTATION
SWIPING RIGHT AND SEXUALLY TRANSMITTED DISEASES (STD):

EXAMINING VENUE SELECTION, RISKY SEXUAL BEHAVIORS, AND STD

AMONG PERSONS LIVING WITH HIV, FLORIDA, 2014-2017
\end{abstract}

by

Isabel Griffin

Florida International University, 2019

Miami, Florida

Professor Gladys E. Ibanez, Major Professor

The incidence of sexually transmitted diseases (STDs) are on the rise, nationwide (World Health Organization, 2015). In Florida, the incidence of bacterial STDs has increased from 425.3 per 100,000 persons per year in 2006 to 684.7 per 100,000 persons per year in 2017 (Florida Charts, 2018). This rise in STDs has gone hand-in-hand with the recent advancement of technology, beginning with at-home internet in the early 1990s to the introduction of social networking smartphone applications (SNSA) on mobile Smartphones in the late 2000s (Grov et al., 2011; Klausner et al., 2011; Winetrobe et al., 2014). In fact, some STDs, such as syphilis, are more common among persons living with HIV/AIDS (PLWHAs) — as one-fourth of HIV-infected patients present with syphilis at the time of HIV diagnosis (Zetola et al., 2007).

There is limited research concerning how persons living with HIV/AIDS (PLWHA) meet sexual partners, specifically by venue type (technology-based vs. in- 
person), and how sociodemographic factors of PLWHA and disclosure of HIV status vary by venue type. The purpose of this dissertation was to examine factors associated with reporting a history of sexually transmitted disease (STD) among Florida Cohort Study participants living with HIV by examining their choice of venue to meet new sexual partners, demographics, and risky sexual behaviors.

The purpose of this dissertation was to examine factors influencing the incidence of sexually transmitted disease (STD) among Florida Cohort Study participants living with HIV by examining their choice of venue to meet new sexual partners, demographics, and risky sexual behaviors. Venue-type was determined based on the method in which participants reported meeting new sexual partners in the prior 12 months. Self-reported lifetime history of sexually transmitted disease and risky sexual behaviors by reported venue-type used to meet sexual partners (“Technology" vs. "Non-Technology") were examined using bivariate and multivariate logistic regression. Factors influencing the incidence of sexually transmitted disease (STD) among Florida Cohort Study were examined utilizing Bayesian network (BN) analysis.

Overall, statistically significant differences were found by venue type and demographics of Florida Cohort Study participants, whether individuals reported a history of sexually transmitted diseases, and reported risky sexual behaviors. Technology-based venues were more commonly associated with younger users and LGBTQ participants. In-person based venues were associated with older participants over 50 years of age. Individuals reporting more than five sexual partners in the prior 12 months were more likely to report a history of syphilis. 


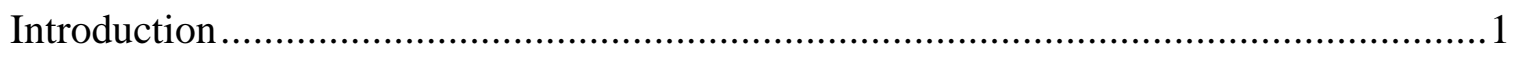

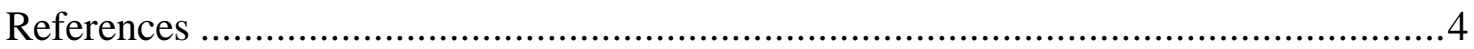

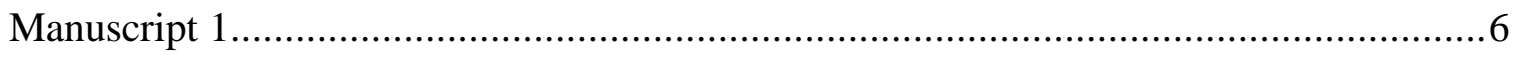

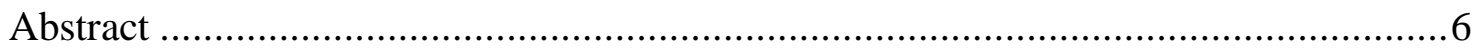

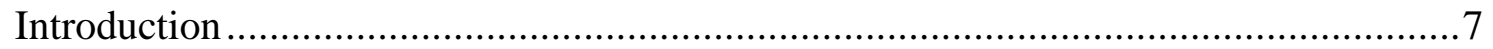

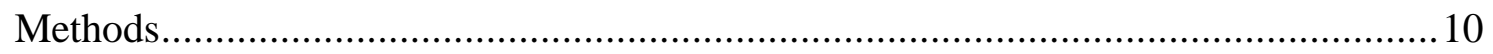

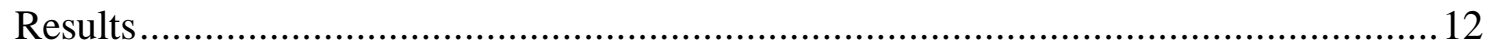

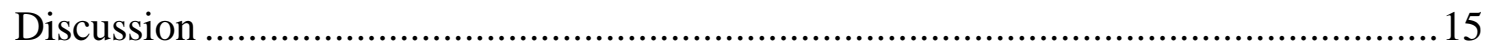

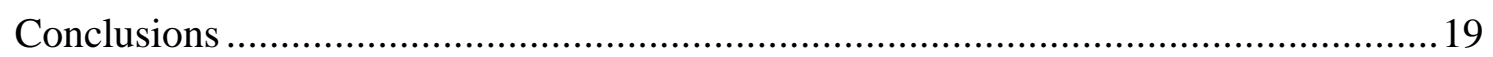

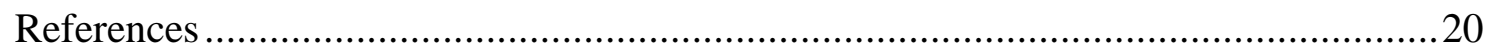

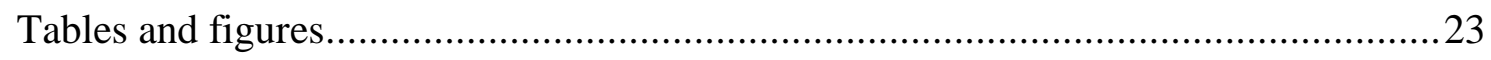

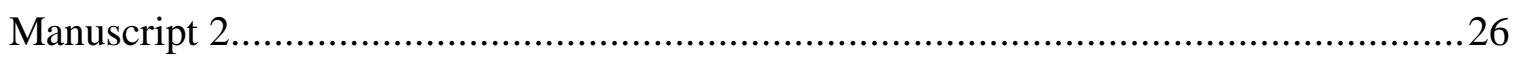

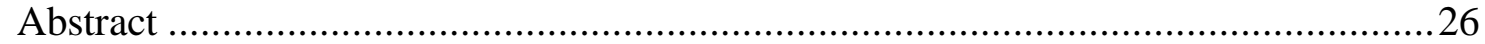

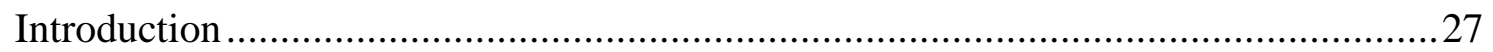

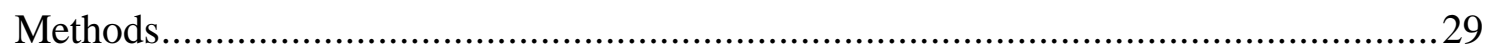

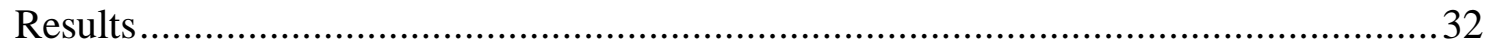

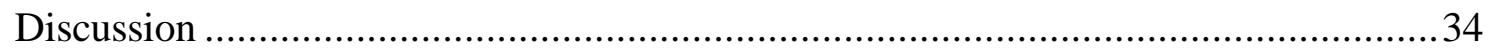

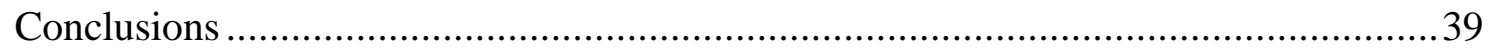

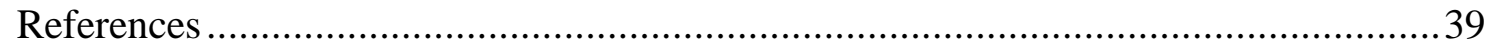

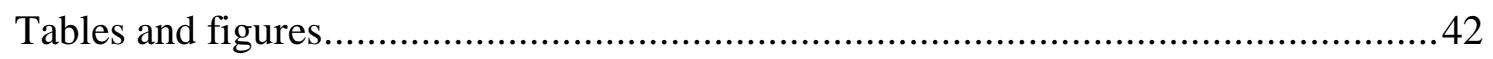

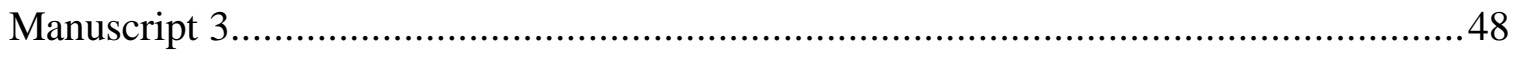

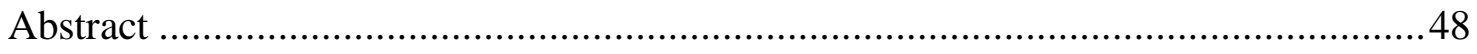

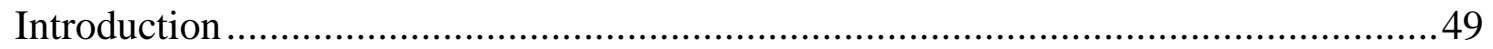

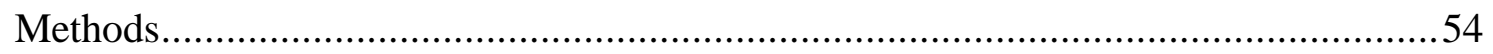

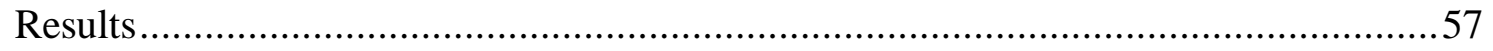

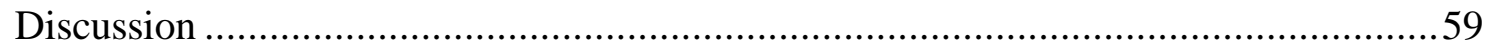

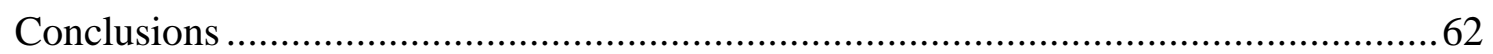

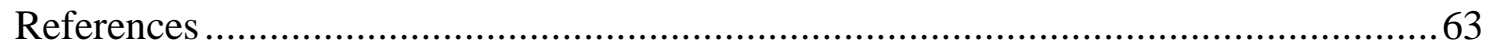

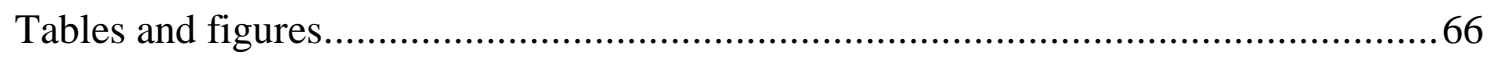

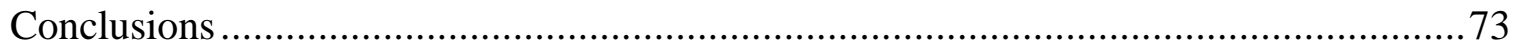

VITA 
TABLES

\section{LIST OF TABLES}

Manuscript 1

Table 1 Demographics of Florida Cohort Study participants by venue-type where they met a small new sexual partner, Florida, 2016.

Table 2 Sex at birth of Florida Cohort Study participants by specific venue where they met a new sexual partner, Florida, 2016.

Table 3 Multivariate logistic regression results for "Technology-only" and "InPerson only" participants compared to "Technology \& In-Person" venue type, Florida, 2016

Manuscript 2

Table 1 Demographic characteristics of Florida Cohort Study Participants using Technology vs. Non-Technology venue types, Florida, 2014-2017

Table 2 Differences in sexual behavior and outcomes of persons living with HIV who met new sexual partners using Technology vs. only Non-Technology venue types, Florida, 2014-2017.

Table 3 Unadjusted and adjusted analyses of Unprotected Sex among Florida Cohort Study participants, Florida, 2014-2017.

Table 4 Unadjusted and adjusted analyses of Syphilis infection among Florida Cohort Study participants, Florida, 2014-2017....

Manuscript 3

Table 1 Top Independent Conditional Probabilities ( $\mathrm{p}$-value > 0.05) contradicting Banjo and/or Literature-based Models $(n=227)$

Table 2 Top Dependent Conditional Probabilities ( $\mathrm{p}$-value $\leq 0.05$ ) contradicting Banjo and/or Literature-based Models (n=227) 


\section{LIST OF FIGURES}

FIGURE

PAGE

\section{Manuscript 3}

Figure 1 GENIE network: A Bayesian Network (BN) structure drawn from the

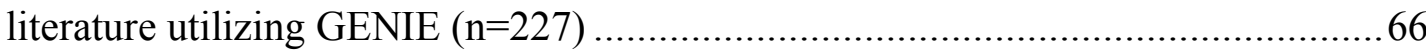

Figure 2 Banjo Network: A Bayesian Network (BN) structure learned from the Florida Cohort Study sample in Banjo scored in $\mathrm{R}$ bnlearn $(\mathrm{n}=227) \ldots \ldots \ldots \ldots \ldots \ldots \ldots \ldots . . . .67$

Figure 3 Bnlearn Network: A Bayesian Network (BN) structure learned from the Florida Cohort Study sample in $\mathrm{R}$ bnlearn package and scored in $\mathrm{R}$ bnlearn $(\mathrm{n}=227)$ 68 


\section{ABBREVIATIONS AND ACRONYMS}

$\begin{array}{ll}\text { MSM } & \text { Men who have sex with men } \\ \text { HIV } & \text { Human immunodeficiency virus } \\ \text { AIDS } & \text { Acquired Immune Deficiency Syndrome } \\ \text { STI } & \text { Sexually transmitted infection } \\ \text { STD } & \text { Sexually transmitted disease } \\ \text { PLWHA } & \text { Persons living with HIV/AIDS } \\ \text { SNSA } & \text { Social Networking Smartphone Application } \\ \text { BN } & \text { Bayesian network } \\ \text { DAG } & \text { Directed Acyclic Graphs } \\ \text { bde } & \text { Bayesian Dirichlet equivalent }\end{array}$




\section{Introduction}

According to the Pew Research Center, the proportion of Americans who have used a dating site and/or mobile application increased from 11 to $15 \%$ between 2013 and 2016 (Smith et al., 2016). Risks associated with the internet and SNSAs have been well established within menwho-have-sex-with-men (MSM) populations. Research has documented a higher number of sexual partners, unprotected sexual acts, consumption of alcohol in conjunction with sexual activity, more sexually transmitted infections among these Internet and SNSA users (McFarlane et al., 2000; Seal et al., 2015; Benotsch et al., 2011; Bull et al., 2000; Garofalo et al., 2007; Horvath et al., 2006; McFarlane et al., 2002; McKirnan et al., 2007; Davis et al., 2006; Landovitz et al., 2013; Lehmiller et al., 2014). However, few studies have examined the internet and SNSA use among heterosexual populations, and among individuals living with HIV. One exception, a recent systematic review, found that risk-taking behavior among heterosexuals had mixed associations between online partner-seeking and condom use or STDs (Binson et al., 2010). However, the review did not consider potential moderators, such as age or gender (Binson et al., 2010).

Research also suggests that venue-specific characteristics, including alcohol in bars and anonymous chat rooms, can impact how MSM negotiate sexual risk behavior. Social norms within each venue have been suggested to play a role in how, for example, MSM negotiate HIVassociated risk behaviors, such as serostatus disclosure and condom use (Binson et al., 2010). However, limited research has been conducted among women, heterosexual men, and people living with HIV. One study found that $43 \%$ of adult women reported having sex with a person they first met on the Internet (McFarlane et al., 2004). These women were also found to have 
higher self-reported rates of STDs, inconsistent condom usage, and reported engaging in anal, oral, and vaginal sex with Internet partners (McFarlane et al., 2004).

Demographics including age group and race/ethnicity have also been found to be associated with technology use to meet sexual partners within MSM populations, but these variables have yet to be examined with regards to modern-day technology in the form of SNSAs (Beymer et al., 2014; Burrell et al., 2012). Overall, very little research has focused on the interaction between technology use, demographics, risky sexual behaviors, and sexually transmitted disease within a non-MSM population. However, a recent systematic review examining risk-taking behavior among heterosexuals found mixed associations between online partner-seeking and condom use or STDs (Tsai et al., 2018).

There is limited research concerning how persons living with HIV/AIDS (PLWHA) meet sexual partners, specifically by venue type (technology-based vs. in-person), and how sociodemographic factors of PLWHA and disclosure of HIV status vary by venue type. The purpose of this dissertation was to examine factors influencing the incidence of sexually transmitted disease (STD) among Florida Cohort Study participants living with HIV by examining participant demographics, risky sexual behaviors, and their choice of venue to meet new sexual partners.

Goal 1 of this dissertation involved analysis of baseline data collected between October 2014 and September 2017 by the Florida Cohort Study (FCS). The characteristics of those who met new sexual partners in the last 12 months by the type of venue used to meet partners was described. Venue-type, such as 'non-technology' or 'technology', was determined based on the method in which participants reported meeting new sexual partners in the prior 12 months. 
Goal 2 of this dissertation involved examining how risky sexual behaviors and sexually transmitted disease prevalence varies among HIV-positive individuals by the venue type used to meet sexual partners. Self-reported lifetime history of sexually transmitted disease and risky sexual behaviors by reported venue-type used to meet sexual partners ("Technology" vs. "NonTechnology") were examined using bivariate and multivariate logistic regression.

Goal 3 of this dissertation involved examining factors influencing the incidence of sexually transmitted disease (STD) among Florida Cohort Study participants by examining participant demographics, risky sexual behaviors, and their choice of venue to meet new sexual partners utilizing Bayesian network (BN) analysis. Bayesian networks are a type of statistical modeling, which allows researchers to obtain a graphical network of variables and outcomes using empirical data. For this study, a total of three networks were developed including one literature-based network and two learned Banjo and bnlearn Bayesian networks. This dissertation represents the first time learned Bayesian networks have been used to predict the probability of sexually transmitted diseases based on an individual's demographics, risky sexual behaviors, and whether they utilize technology to meet to sexual partners.

This dissertation contributes to the field specifically by examining factors associated with STDs, risky sexual behaviors, and venue type among non-MSM population living with HIV, which could help with STD prevention planning for this high-risk group. Secondly, it contributes to the field generally, by examining individuals at higher risk for STDs among those who are living with HIV using technology to meet sexual partners; this will help to advance the understanding within the public health community concerning this population. These findings highlight the need for future research examining venue type especially among minorities, such as women and heterosexual populations. 


\section{References}

Benotsch, E. G., Martin, A. M., Espil, et al. "Internet use, recreational travel, and HIV risk behaviors in men who have sex with men." J Community Health. 2011. (36):398-405.

Beymer M., Weiss R., Bolan R. , et al. "Sex on demand: geosocial networking phone apps and risk of sexually transmitted infections among a cross-sectional sample of men who have sex with men in Los Angeles county." Sex Transm Inf. 2014. 90:567-572.

Binson D, Pollack LM, Blair J, et al. "HIV transmission risk at a gay bathhouse.” J Sex Res. 2010. 47(6):580-588.

Burrell E. Pines H., Robbie E., et al. "Use of the location-based social networking application GRINDR as a recruitment tool in rectal microbe development research." AIDS Behav. 2012. 16:1816-1820.

Bull, S., \& McFarlane, M. "Soliciting sex on the Internet - what are the risks for sexually transmitted diseases and HIV? "Sex Transm Dis. 2000. 27(9): 545-550.

Davis M. "Sex and the Internet: Gay men, risk reduction and serostatus." Cult Health Sex. 2006. 8:161174.

Florida Charts. Total Bacterial STDs. Florida Department of Health, Bureau of Communicable Diseases. 2018. Retrieved from:

http://www.flhealthcharts.com/charts/OtherIndicators/NonVitalSTDDataViewer.aspx?cid=9767

Garofalo, R., Herrick, A., Mustanski, B.S., et al. "Tip of the iceberg: Young men who have sex with men, the Internet, and HIV risk.” Am J Public Health. 2007. (97):1113-1117.

Grov, Christian, et al. "Exploring the Venue: Role in Risky Sexual Behavior Among Gay and Bisexual Men: An Event-Level Analysis from a National Online Survey in the U.S.” Arch Sex Behav. 2011. 42 (2): 291-302.

Horvath, K.J., Bowen, A.M., Williams, M.L. "Virtual and physical venues as contexts for HIV risk among rural men who have sex with men." Health Psychol. 2006. (25): 237-242.

Klausner J. Chapter 13: Tracking a Syphilis Outbreak Through Cyberspace. Cases in Field Epidemiology: A Global Perspective. Sudbury, MA: Jones \& Bartlett Learning. 2011. (13): 163-71.

Landovitz, et al. "Epidemiology, Sexual Risk Behavior, and HIV Prevention Practices of Men who have Sex with Men Using GRINDR in Los Angeles, California.” J Urban Health. 2013. 90(4): 729-739.

Lehmiller, et al. "Social networking Smartphone applications and sexual health outcomes among men who have sex with men." PloS One. 2014. 9(1): e86603.

McFarlane, M., Bull, S. S., Rietmeijer, C. "The Internet as a newly emerging risk environment for sexually transmitted diseases.” JAMA. 2000. 284(4): 443-446.

McFarlane, M., Bull, S.S., Rietmeijer, C.A, et al. "Young adults on the Internet: Risk behaviors for sexually transmitted diseases and HIV." J Adolesc Health. 2002. (31): 11-16. 
McFarlane M., Kachur R., et al. "Women, the Internet, and Sexually Transmitted Infections." J Women's Health. 2004.13 (6): 689-694.

McKirnan, D., Houston, E., Tolou-Shams, M. "Is the Web the culprit? Cognitive escape and Internet sexual risk among gay and bisexual men.” AIDS Behav. 2007. (11): 151-160.

Seal DW, Benotsch EG, Green M, et al. "The use of internet chat rooms to meet sexual partners: A comparison of non-heterosexually identified men with heterosexually identified men and women." Int J Sex Health. 2015. 27(1):1-15.

Smith A. "15\% of American adults have used online dating sites or mobile dating apps." 2016. Retrieved from: https://www.pewinternet.org/2016/02/11/15-percent-of-american-adults-have-used-online-datingsites-or-mobile-dating-apps/

Tsai J, Sussman S, Pickering T. "Is Online Partner-Seeking Associated with Increased Risk of Condomless Sex and Sexually Transmitted Infections Among Individuals Who Engage in Heterosexual Sex? A Systematic Narrative Review.” 2018. Arch Sex Behav. 48(2): 533-555.

World Health Organization. "Global Estimates Shed Light on Toll of Sexually Transmitted Infections." 2015. Retrieved from: http://www.who.int/reproductivehealth/news/stis-estimates-2015/en/

Winetrobe H, Rice E, Bauermeister J, et al. "Associations of Unprotected Anal Intercourse with Grindrmet Partners among Grindr-using Young Men Who Have Sex with Men in Los Angeles.” 2014. AIDS Care. 26(10): 1303-308.

Zetola N, Klausner J. “Syphilis and HIV Infection: An Update.” 2007. Clin Infect Dis. 44 (9): 1222_1228. 


\section{Manuscript 1}

C Copyright 2019

\section{Methods of meeting new sexual partners among persons living with HIV by physical and virtual venue type by demographic and HIV status disclosure, Florida, 2014-2017}

\section{Abstract}

There is limited research concerning how persons living with HIV/AIDS (PLWHA) meet sexual partners, specifically by venue type (technology-based vs. in-person), and how sociodemographic factors of PLWHA and disclosure of HIV status vary by venue type. Analysis of baseline data collected between October 2014 and September 2017 by the Florida Cohort Study. Venue-type was determined based on the method in which participants reported meeting new sexual partners in the prior 12 months (technology-only, in-person only, technology \& inperson). Demographics and HIV status disclosure were analyzed by venue type. Among the total FCS (n=936), $199(21.2 \%)$ met the inclusion criteria for this study (report meeting a new sexual partner in the prior 12 months). Among 199 participants, $89.5 \%$ were male, $40.7 \%$ were African American, 67.3\% reported their sexual orientation as gay or lesbian, and the median age was 44 years (range 20-66). Multivariate logistic regression found that participants who reported "technology-only" methods were younger compared to individuals who reported using both “technology \& in-person" methods. Similar analyses found that individuals who reported "inperson" only venues were less likely to report being gay/lesbian, more likely to be over the age of 50, and were less likely to report being Non-Hispanic White compared to participants who reported using both "technology \& in-person" methods. HIV status disclosure to casual sexual partners did not vary by venue type. This was the first study to examine venues where middle- 
aged, individuals living with HIV, meet sexual partners in the age of technology. This study found that within this HIV positive cohort those who reported using "technology-only" methods were younger and LGBTQ, and those who reported using "in-person" only methods were older (over 50 years).

KEYWORDS: HIV, AIDS, Characteristics, Internet, Social Networking Smartphone Applications

Introduction

Since the late 1990s, online chat rooms via the Internet have facilitated opportunities to meet individuals looking to have sexual encounters. The Internet allows for the social networking of individuals who may not meet via other venues thereby increasing likelihood of contracting an STD through access to multiple sexual partners (Seal et al., 2015). The risks associated with the Internet have been well established in the past, as researchers have documented a higher number of sexual partners, more unprotected sexual acts, higher consumption of alcohol in conjunction with sexual activity, and more sexually transmitted infections among these internet-users compared to non-internet users (Seal et al., 2015; Benotsch et al., 2011; Bull et al., 2000; Garofalo et al., 2007; Horvath et al., 2006; McFarlane et al., 2002; McKirnan et al., 2007). The Internet allows users to anonymously explore sexual relationships with accessibility to several potential sexual partners (McFarlane et al., 2000). However, the role of the Internet in these virtual networks has evolved as technology has advanced — specifically with the introduction of the Smartphone in 2007.

The SNSA, Grindr, was introduced in 2009 (Grindr 2016). Grindr, an app geared towards a gay, bisexual, and bi-curious male audience, allows users to virtually connect with individuals 
all over the world. Now with a swipe of a finger, users can connect with a complete stranger aided by geospatial mapping software that shows the exact distance (in feet) they need to travel in order to meet. This web-based technology not only facilitates the meeting of two individuals, but also increases the circumference of a user's sexual network via their Smartphone by expanding a user's social network (Winetrobe et al., 2014).

Previous research has noted that men-who-have-sex-with-men (MSM) users of Smartphone applications report higher engagement in risky sexual behaviors, which include unprotected anal sex and having a higher number of sexual partners. In a study by Winetrobe et al., 20\% of 146 MSM reported having unprotected anal sex with Grindr-met partners (Winetrobe et al., 2014). In a study by Landovitz et al. surveying 375 young MSM in Los Angeles between 2010-2011: 52.8\% of participants did not always ask sex partners about their HIV status; 56\% met sexual partners in the past 3 months via Grindr, $40 \%$ via internet sex-focused websites, $37.1 \%$ at bars, $33.3 \%$ at dance clubs, and $25.1 \%$ at internet dating websites (Landovitz et al, 2012).

Using the Internet versus in-person methods to meet sexual partners depends on a variety of factors including the "urgency" for sex or when experiencing depression or low confidence (Ross et al., 2007). Studies examining differences by venue-type found that participants, both MSM and non-MSM, preferred meeting individuals face-to-face (without the internet) when alcohol and drugs were used and when the intention was to meet a partner to form a relationship (Seal et al., 2015; Rosser et al., 2017). Current research suggests that venue-based characteristics (i.e. alcohol in bars, anonymous online chat rooms, and other venues) can impact how MSM negotiate sexual risk behavior (Ross et al., 2007). For example, studies have shown that users utilize the internet to anonymously explore sexual relationships. Social norms within each venue can play a role in how MSM negotiate HIV-associated risk behaviors (i.e. serostatus disclosure, 
condom use) (Grov et al., 2012). It is also noted that venues can play a role in both the promotion and prevention of the spread of STDs. For example, HIV status disclosure was lowest among men who met their most recent partner in a park, outdoors, or other public place and highest among men who met their most recent partner online; which contradicts the findings in the study by Landovitz et al. (Grov et al., 2011; Landovitz et al., 2012). However, to date, no studies have been conducted examining venue type among heterosexual users.

Significant research has been conducted within venues (recruiting participants using a Smartphone application or while at a club), but little research has been conducted examining demographic differences and behaviors across venues (Heijman, et al., 2016; Grov et al., 2012; Wong et al., 2014). Within these populations, risky sexual behavior and incidence of sexually transmitted diseases has varied by venue type (Kerr et al., 2015; Heijman et al., 2016; Grov et al., 2012; Wong et al., 2014). Grov et al. found that alcohol use prior to/during last sexual encounter was highest among men who met their most recent partner in a bathhouse or in a bar/club (Grov et al., 2011).

To date, there is a lack of understanding regarding who is using these online and offline methods to meet sexual partners, and whether there are any demographic differences between single vs. multiple venue users. One theory, the Social Network Homophily theory, refers to the clustering of similar individuals within networks (McPherson et al., 1996). As such, individuals within certain venues may share certain demographic and HIV characteristics.

There are significant gaps in knowledge concerning how PLWHA meet new sexual partners, especially in the age of technology. To the author's knowledge, studies have yet to examine these gaps in knowledge regarding heterosexual and racially diverse populations living with HIV/AIDS. Understanding the demographics of those using these venues is essential to 
crafting targeted prevention messaging. The Florida Cohort Study collects self-reported information about demographic and behavioral factors that may affect health outcomes for persons with HIV/AIDS. The purpose of this study is to examine the characteristics of persons living with HIV who are in the Florida Cohort Study by demographics and venue type used to meet new sexual partners. This study attempts to fill gaps in knowledge concerning how individuals meet sexual partners in the age of technology by examining sociodemographic factors and HIV-related characteristics by venue type. We hypothesize that individuals who met a sexual partner through “technology-only" venues will differ by age, sex at birth, education, sexual orientation, and HIV disclosure history compared to those who met new sexual partners via "in-person only" or “technology \& in-person” venue-types.

Methods

Between October 2014 and September 2017, 936 PLWHA were recruited into the Florida Cohort Study. The Florida Cohort Study recruited from a collaborative network of county health department and community clinics and settings throughout Florida, including sites at Lake City, Gainesville, Tampa, Orlando, Sanford, Ft. Lauderdale, and Miami. Inclusion criteria for the study include being over the age of 18 , HIV positive, and living in the state of Florida. After written informed consent was obtained, participants completed a Research Electronic Data Capture (REDCap®) survey in English or Spanish. Surveys took approximately 30-45 minutes to complete, and participants were provided a \$25 gift card upon completion. The survey asked participants questions about their demographics, how they met new sexual partners in the past 12 months (defined in this study as venue), and questions regarding HIV disclosure. The Florida 
Cohort Study was approved by Institutional Review Boards (IRBs) at the University of Florida, Florida International University, and the Florida Department of Health.

\section{Measures}

For the present study, we conducted a secondary analysis of baseline data collected from the Florida Cohort Study. Demographic variables of interest included within our study were age (median, range), age-group (18-24, 25-29, 30-39, 40-49, $\geq 50)$, sex at birth (male or female), race/ethnicity (Non-Hispanic White, Non-Hispanic Black, Hispanic, Other), education level (high school or below, some college or some tech/trade school, college/trade school, or graduate degree/professional degree), self-reported sexual orientation (heterosexual, gay or lesbian, bisexual), and relationship status (single vs. non-single).

Frequency of disclosing HIV status to casual sexual partners was also captured in the survey. Participants were asked, "How many of the following groups of people have you told about your HIV status?". One of the groups was listed as “casual sex partners" for which respondents could answer "None or hardly any," Some", "Most or all", or "Not applicable". For individuals who responded to the HIV status disclosure question as "Not-Applicable," it was assumed that this meant they did not report having "casual” sexual partners. However, "casual sex partner" was not defined in the FCS questionnaire.

Venue-type was determined based on how participants responded to locations where they had met new sexual partners in the last 12 months (internet, SNSAs, bar, club, bathhouse, massage parlor, work, and/or friend, and other). Given small samples sizes for some locations, individual venues were grouped into venue-types: "Technology-Only" (Internet and/or SNSAs), "In-Person Only" (bar or club, and/or bathhouse, and/or massage parlor, and/or work, and/or 
friend), or "Technology \& In-Person" ("Internet and/or SNSAs" AND "bar or club, and/or bathhouse, and/or massage parlor, and/or work, and/or friend) (Table 1). The Florida Cohort Study did not ask for additional information concerning "Other", so at this current time it is unknown what other venues fall into the category of "Other". Individuals who did not report meeting a new sex partner in the prior 12 months, reported being asexual, reported "other" as a venue where they met a recent sexual partner, and had missing variables (unknowns) were excluded from analysis.

\section{Data Analysis Plan}

Descriptive statistics and frequencies were calculated for participants by venue-type. Characteristics within each venue-type were examined using two multivariate logistic regression models (using an alpha of 0.05 for significance). The two models compared participants reporting 1) "Technology only" and 2) "In-person only" venues to participants reporting "Technology \& In-person" venues. This analysis allowed for direct comparisons in how various demographic and HIV status disclosure to casual sex partners varied by venue-type. All statistical analyses were performed using SAS $®$ software, version 9.4.

Results

\section{Demographics of Participants}

Among the 936 respondents, 737 were excluded from analysis, as they did not meet the inclusion criteria for this study. Participants were excluded after not reporting a venue where they had met a new sexual partner $(n=417)$, reported being asexual $(n=9)$, reported the "other" venue ( $n=73)$, and did not answer the question concerning specific venue type $(n=238)$. The 
individual characteristics of the 199 participants meeting the inclusion criteria are presented in Table 1. Most participants were male $(89.5 \%)$, and over the age of $40(n=117 ; 58.8 \%)$ with the median age of the group being 44 years (range of $20-66$ ). Half of participants were NonHispanic Black/African American [81 (40.7\%)], the rest were Non-Hispanic White [58 (29.2\%)], Hispanic [44 (22.1\%)], and Other [16 (8.0\%)].

When asked about highest level of education attained $(n=196), 98(50.0 \%)$ reported the highest level of education to be high school or below, 54 (27.6\%) as some college or tech/trade school, 29 (14.8\%) college/trade school, and 15 (7.7\%) with a graduate/professional degree. When asked about their relationship status, 174 (87.4\%) participants reported being single and $25(12.6 \%)$ reported being married (Table 1). A total of 132 (67.3\%) reported their sexual orientation as gay or lesbian, while $41(20.6 \%)$ reported being heterosexual, and $21(10.6 \%)$ bisexual (Table 1).

A total of $43(21.6 \%)$ participants reported meeting new sexual partners in the prior 12 months via "technology-only" venues (Table 1). A total of 71 (35.7\%) participants reported venues that fell into the "in-person only" category (Table 1). A total of 85 (42.7\%) participants reported venues that fell into the "technology \& in-person" category (Table 1).

The most frequently reported venue where participants reported meeting sexual partners is on the internet $(\mathrm{n}=105,52.8 \%)$. Distribution of specific venue by gender at birth is presented in Table 2. Several venues were significantly associated with males, including meeting a partner via a friend, the internet, bar or club, phone app, and bath house $(\mathrm{p}<0.05)$. Among the participants, $97.6 \%$ and $100 \%$ of participants who reporting using a phone app or bath house to meet new sexual partners, respectively, were male. 


\section{Technology-only}

Multivariate logistic regression found that participants who reported "technology-only" methods were 5.52 times more likely to be 25 - 29 years of age compared to individuals who reported using both "technology \& in-person" methods (i.e. utilized multiple venue types) (reference age group 30-39 years) (Table 3). No statistically significant differences were found in sex at birth, race/ethnicity, education level, sexual orientation, and relationship status compared to individuals whom met sexual partners using both "technology and in-person" venues (i.e. multiple venue types) (Table 3).

\section{In-Person only}

Multivariate logistic regression found that individuals who reported "in-person" only venues were 5.81 times more likely to report being over the age of 50 years compared to individuals who utilized both technology and in-person venues (i.e. multiple venue types). In addition, "in-person” only participants were less likely to report being Non-Hispanic White and gay/lesbian compared to participants who reported using both "technology \& in-Person" methods (Table 3). No statistically significant differences were seen in sex at birth, education level, or relationship status.

\section{HIV-status disclosure}

A total of $105(52.7 \%)$ participants reported disclosing HIV status to casual sexual partners "most or all of the time," 23 (14.4\%) "none or hardly any," 33 (16.2\%) "some," and 32 (20.0\%) responded to this question as "not applicable" (Table 1). HIV status disclosure among 
individuals reporting "in-person only" appeared to be lower than "technology-only" and "technology and in-person". However, this was not statistically significant.

\section{Discussion}

This study is one of the first to examine the characteristics of a diverse sample of PLWHA in the state of Florida by the venue-types where they met new sexual partners. This study also compared venue-types from a sample that was not recruited using venue-based sampling. Furthermore, this is the first study to attempt to examine whether sexual orientation and race/ethnicity play a role in venue type selection among PLWHAs. This study found more participants reported utilizing "technology \& in-person" methods to meet sexual partners than "technology-only" methods. Previous literature examining the utilization of venue type examined the venues individually and found similar findings concerning participants reporting the utilization of multiple venue types (for example using the internet, bar, and bathhouses to meet sexual partners) (Grov et al., 2011; Grov et al., 2012). Grouping within the Florida Cohort Study cohort by venue-type also found significant differences by age, race/ethnicity, and sexual orientation when single venue-type ("technology-only" or "in-person" only) was compared to multiple venue types ("technology \& in-Person).

\section{Demographics}

Young people living with HIV/AIDS (25-29 years) were more likely to report utilizing "technology-only" venues than both "technology \& in-person" venues, which is consistent with the literature that primarily focuses on people not living with HIV/AIDS (Rendina et al., 2014). This finding suggests that younger adults between the ages of 25-29 may feel more comfortable 
utilizing technology to meet sexual partners as opposed to more traditional in-person venues. This finding suggests that targeted prevention messaging for young PLWH, such as the $\mathrm{U}=\mathrm{U}$ campaign or from organizations such as the Florida Department of Health or the Florida Cohort Study whose clients were participants in this study, should utilize technology methods. Interestingly, there was no association between Non-Hispanic White and a specific venue type; which is in contrast to the literature, which found associations between utilizing technology-based venues and being a NonHispanic White MSM (Garofalo et al., 2007; Beymer et al., 2014; Grov et al., 2012; Rendina et al., 2014). Our study also found that individuals over the age of 50 years were more likely to report "in-person" venues. This could be because of the recent evolution of technology-primarily targeted towards younger users looking to "swipe right" - as older populations may prefer pretechnology in-person methods of meeting sexual partners.

\section{Sexual Orientation}

Within the FCS cohort, there were significant differences in venue type by sexual orientation as gay/lesbian participants were less likely to report "in-person" than both “technology \& in-person” venues. Previous studies primarily focused on mixed-HIV status MSM did not find associations between sexual orientation and venue type populations; however, associations were found in our study among PLWHAs which suggest that LGBTQ members living with HIV are moving from utilizing solely "in-person" venues to meet new sexual partners via technology-based venues (Grov et al., 2011; Grov et al., 2012). This finding may be due to the preference of LBGTQ individuals to use the internet and SNSAs to connect with others in the LBGTQ community, especially in situations where individuals experience social stigma related to their orientation (Magee et al., 2012). Individuals may also be utilizing technology-based 
venues to engage in serosorting (a common practice among MSM); however, future studies are needed to examine this further (Suarez et al., 2001; Rietmeijer et al, 2007; Eaton et al., 2011).

\section{Disclosure of HIV status}

The FCS cohort did not identify statistically significant differences in HIV disclosure among "technology-only" and "in-person only" participants compared to "technology \& inperson," which is not substantiated by the literature (Grov et al., 2011). As previously cited in the literature, HIV status disclosure was lowest among men who met their most recent partner in a park, outdoors, or other public place and highest among men who met their most recent partner online (Grov et al., 2011). Our lack of association between HIV status disclosure and venue type was unexpected and contrary to the literature.

\section{Implications}

Prior to this study, very limited research has been conducted examining venue type and PLWHA. The implications of this study highlight possible opportunities to reach HIV positive individuals in the physical space where they are meeting their sexual partners. As access to the Internet is expanding through smartphones and tablets, this technology may serve as a venue for HIV/STD health education. Gabarron et al. found significant evidence of social media interventions (Facebook, MySpace, YouTube, etc.) in promoting sexual health (Gabarron et al., 2016). In 2012, a study by Jones et al. identified 641 app users on Grindr interested in HIV selftesting (Jones et al., 2012). In our own FCS, Lucero et al. found that $85.5 \%$ of participants were interested in using a free mobile phone app that supports HIV self-management (Lucero et al., 2017). There are many opportunities to use the information gained from this study to create 
"Swipe Smart" interventions geared towards high-risk Internet and SNSA users, and especially those living with HIV. This study could be used to create targeted health interventions, such as educating on the importance of HIV disclosure to casual sexual partners and regular HIV testing. In addition, based on the findings of this research, interventions tailored to LGBT technology users between the ages of $25-29$ who are more likely to use "technology-only" venues (like social networking smartphone applications and the Internet) would be useful in order to appeal to the demographics of those most at-risk. Future research should also examine the role of reported "venue-type" regarding engaging in risky sexual behaviors and reporting recent STD infections.

\section{Limitations}

There were several limitations identified in this study. Due to the strict inclusion criteria of this study over half of the original sample was excluded from analysis. The majority of participants were excluded after not reporting a venue where they had met a new sexual partner $(n=417)$, reported being asexual $(n=9)$, reported the "other" venue $(n=73)$, and had missing or unknown data for their specific venue type ( $\mathrm{n}=238$ ). Florida Cohort Study respondents were given an "other" option for venue type, but the survey did not ask participants to further elaborate on "other" locations. As such, specifics regarding these locations (and whether these other venues would have been considered in-person vs. technology-based) are unknown. As such, these individuals were excluded from the study. Due to small sample sizes we were unable to individually examine the association between specific characteristics and specific venues. Also, this study used a convenience sampling framework and may not be generalizable to the entire state of Florida. This was also a cross-sectional study and may not reflect temporal changes nor can causal associations be determined. Furthermore, casual sex partners was not 
defined in the survey. Finally, due to the self-report nature of the survey there may be social desirability bias in the reporting of venues, especially disclosure of utilizing bathhouses and massage parlors to meet sexual partners. However, this is the first time HIV status disclosure by venue type has been examined among such a large sample size of PLWHAs.

\section{Strengths}

Overall, this study has several strengths. This was the first study to have a study population of only PLWHAs by location of meeting sexual partners in the state of Florida. This study found that the association between age, sexual orientation, and use of technology-based venues among PLWHAs was consistent with literature studying HIV negative populations. This study added to the literature concerning partner meeting behaviors among individuals living with HIV. In addition, this study was unique in that it examined venue-type within an ethnically and geographically diverse, as well as middle-aged, PLWHA cohort.

\section{Conclusions}

Our findings, consistent with the current literature, suggest that differences in venue selection may vary depending on the demographics and sexual orientation of the population. This study found that within this HIV positive cohort those who reported using "technology-only" methods were younger and LGBTQ, and those who reported using "in-person" only methods were older (over 50 years). This unique study, which describes a population of individuals living with HIV in the context of technology, in-person, and multiple venue types suggests that future studies should examine attitudes and behaviors behind venue type selection. 


\section{References}

Benotsch, E, Martin A, Espil F, et al. "Internet use, recreational travel, and HIV risk behaviors in men who have sex with men. 2011." J Community Health. 36:398-405.

Beymer M, Weiss R, Bolan R, et al. "Sex on demand: Geosocial networking phone apps and risk of sexually transmitted infections among a cross-sectional sample of men who have sex with men in Los Angeles county.” 2014. Sex Trans Inf. 90(7): 567-572.

Bull, S., \& McFarlane, M. "Soliciting sex on the Internet - what are the risks for sexually transmitted diseases and HIV." 2000. Sex Trans Dis. 27(9): 545-550.

Eaton L, Kalichman S, Cain D, et al. "Serosorting Sexual Partners and Continued Risk for HIV Transmission among Men who have Sex with Men.” 2011. Am J Prev Med. 33(6):479-485.

Esser S, Krozek K, Dirks H, et al. "Sexual Risk Behavior, Sexually Transmitted Infections, and HIV Transmission Risks in HIV-Positive Men Who Have Sex with Men (MSM) - Approaches for Medical Prevention.” 2017. J Dtsch Dermatol Ges. 15(4):421-428.

Gabarron E and Wynn R. "Use of Social Media for Sexual Health Promotion: a Scoping Review." 2016. Global Health Action. 9 (1): e32193

Garofalo R, Herrick, A, Mustanski B, \& Donenberg, G. "Tip of the iceberg: Young men who have sex with men, the Internet, and HIV risk.” 2007. Amer J Public Health. 97:1113-1117.

Grindr. "Grindr | The World's Largest Gay Social Network App." 2016. Grindr.

Grov C, et al. "Exploring the Venue: Role in Risky Sexual Behavior Among Gay and Bisexual Men: An Event-Level Analysis from a National Online Survey in the U.S.” 2011. Arch Sex Behav. 42(2): 291-302.

Grov C, et al. "Attitudes about and HIV risk related to the 'Most Common Place' MSM meet their sex partners: comparing men from bathhouses, bars/clubs, and craigslist.org." 2012. AIDS Edu Prev. 24(2): 102-116.

Heijman T, Stolte I, Geskus R, et al. "Does online dating lead to higher sexual risk behavior? A cross-sectional study among MSM in Amsterdam, the Netherlands." 2016. BMC Inf Dis. 16: 288.

Horvath K, Bowen A, \& Williams M. "Virtual and physical venues as contexts for HIV risk among rural men who have sex with men." 2006. Health Psychology. 25: 237-242.

Jones K, Baldwin K, Lewis P. "The potential influence of a social media intervention on risky sexual behavior and chlamydia incidence.” 2012. J Community Health Nurs. 29: 106-120. 
KerrKerr Z, Pollack L, Woods W, Blair J, Binson D. "Use of multiple sex venues and prevalence of HIV risk behavior: identifying high risk MSM.” 2015. Arch Sex Behav. 44(2): 443-451.

Lehmiller JJ, Loerger M. "Social networking Smartphone applications and sexual health outcomes among men who have sex with men.” 2014. PloS One. 9(1): e86603.

Landovitz R, Tseng C, Weissman M, et al. "Epidemiology, Sexual Risk Behavior, and HIV Prevention Practices of Men who have Sex with Men Using GRINDR in Los Angeles, California.” 2012. J Urban Health. 90(4): 729-739.

Lucero R, Frimpong J, Fehlberg E, et al. "The Relationship Between Individual Characteristics and Interest in Using a Mobile Phone App for HIV Self-Management: Observational Cohort Study of People Living With HIV.” 2017. JMIR Mhealth Uhealth. 5(7):e100.

Magee J, Bielow L, Dehann S, Mustanski B. "Sexual Health Information Seeking Online: A Mixed-Methods Study Among Lesbian, Gay, Bisexual, and Transgender Young People." 2012. Health Educ Behav. 39 (3): 276-289.

McFarlane, M., Bull, S. S., \& Rietmeijer, C. "The Internet as a newly emerging risk environment for sexually transmitted diseases.” 2000. JAMA. 284(4): 443-446.

McFarlane, M., Bull, S. S., \& Rietmeijer, C. A. "Young adults on the Internet: Risk behaviors for sexually transmitted diseases and HIV." 2002. J Adolesc Health. 31: 11-16.

McKirnan D, Houston E, \& Tolou-Shams M. "Is the Web the culprit? Cognitive escape and Internet sexual risk among gay and bisexual men.” 2007. AIDS Behav. 11:151-160.

McPherson M, Smith-Lovin L, Cook J. "Birds of a Feather: Homophily in Social Networks." 2001. Annual Rev Sociology. 27(1): 415 - 444.

Rietmeijer CA, Lloyd LV, McLean C. "Discussing HIV serostatus with prospective sex partners: A potentional HIV prevention strategy among high-risk men who have sex with men." 2007. Sex Trans Dis. 34:215-219.

Rendina H, Jimenez R, Grov C, Ventuneac A \& Parsons J. "Patterns of lifetime and recent HIV testing among men who have sex with men in new york city who use grindr." 2014. AIDS Behav. 18(1): 41-49.

Ross M, Rosser B, McCurdy S, Feldman J. "The advantages and limitations of seeking sex online: A comparison of reasons given for online and offline sexual liaisons by men who have sex with men.” 2007. J Sex Res. 44: 59-71.

Seal D, Benotsch E, Green M, et al. "The use of internet chat rooms to meet sexual partners: A comparison of non-heterosexually identified men with heterosexually identified men and women." 2015. Int J Sex Health. 27(1):1-15. 
Suarez T, Kelly J, Pinkerton S, et al. “Influence of a partner's HIV serostatus, use of highly active antiretroviral therapy, and viral load on perceptions of sexual risk behavior in a community sample of men who have sex with men." 2001. JAIDS. 28:471-7.

Winetrobe H, Rice E, Bauermeister J, Petering R, Holloway I. "Associations of Unprotected Anal Intercourse with Grindr-met Partners among Grindr-using Young Men Who Have Sex with Men in Los Angeles.” 2014. AIDS Care. 26(10): 1303-308.

Wong, Mee Lian, et al. "Men seeking sex online practice riskier sexual behaviors than men frequenting brothels: survey findings from Singapore." 2014. Sex Trans Infect. 90: 401-407. 
Table 1. Demographics of Florida Cohort Study participants by venue-type where they met a new sexual partner, Florida, 2016*

\begin{tabular}{|c|c|c|c|c|}
\hline & $\begin{array}{c}\text { Total } \\
(\mathrm{n}=199)\end{array}$ & $\begin{array}{c}\text { Technology only } \\
(\mathrm{n}=43)\end{array}$ & $\begin{array}{c}\text { In-Person only } \\
(\mathrm{n}=71)\end{array}$ & $\begin{array}{c}\text { Technology \& In-Person } \\
(\mathrm{n}=85)\end{array}$ \\
\hline Demographic variables & $n(\%)$ & $n(\%)$ & $n(\%)$ & $n(\%)$ \\
\hline \multicolumn{5}{|l|}{ Age } \\
\hline $18-24$ & $23(11.6)$ & $8(18.6)$ & $4(5.6)$ & $11(12.9)$ \\
\hline $25-29$ & $19(9.6)$ & $8(18.6)$ & $3(4.2)$ & $8(9.4)$ \\
\hline $30-39$ & $40(20.1)$ & $7(16.3)$ & $11(15.5)$ & $22(25.9)$ \\
\hline $40-49$ & $61(30.6)$ & $12(27.9)$ & $23(32.4)$ & $26(30.6)$ \\
\hline$\geq 50$ & $56(28.1)$ & $8(18.6)$ & $30(42.3)$ & $18(21.2)$ \\
\hline \multicolumn{5}{|l|}{ Sex at Birth } \\
\hline Male & $178(89.4)$ & $39(90.7)$ & $56(78.9)$ & $83(97.7)$ \\
\hline Female & $21(10.6)$ & $4(9.3)$ & $15(21.1)$ & $2(2.3)$ \\
\hline \multicolumn{5}{|l|}{ Race/Ethnicity } \\
\hline Non-Hispanic White & $58(29.2)$ & $9(20.9)$ & $12(16.9)$ & $37(43.5)$ \\
\hline Non-Hispanic Black & $81(40.7)$ & $17(39.5)$ & $40(56.3)$ & $24(28.2)$ \\
\hline Hispanic & $44(22.1)$ & $12(27.9)$ & $15(21.1)$ & $17(20.0)$ \\
\hline Other & $16(8.0)$ & $5(11.7)$ & $4(5.7)$ & $7(8.2)$ \\
\hline \multicolumn{5}{|l|}{ Education Level } \\
\hline High School or below & $98(50.0)$ & $21(48.8)$ & $46(67.7)$ & $31(36.5)$ \\
\hline Some college/tech/trade & $54(27.6)$ & $13(30.2)$ & $10(14.7)$ & $31(36.5)$ \\
\hline College/Trade school & $29(14.8)$ & $5(11.6)$ & $8(11.8)$ & $16(18.8)$ \\
\hline Graduate/Prof. degree & $16(7.6)$ & $4(9.3)$ & $4(5.8)$ & $7(8.2)$ \\
\hline \multicolumn{5}{|l|}{ Sexual Orientation } \\
\hline Heterosexual & $41(20.6)$ & $5(11.6)$ & $30(42.3)$ & $6(7.0)$ \\
\hline Gay or Lesbian & $134(67.3)$ & $33(76.8)$ & $27(38.0)$ & $74(87.1)$ \\
\hline Bisexual & $21(10.6)$ & $4(9.3)$ & $13(18.3)$ & $4(4.7)$ \\
\hline Other & $3(1.5)$ & $1(2.3)$ & $1(1.4)$ & $1(1.2)$ \\
\hline \multicolumn{5}{|l|}{ Relationship Status } \\
\hline Married/Long-term partner & $25(12.6)$ & $37(86.1)$ & $62(87.3)$ & $75(88.2)$ \\
\hline Single/Divorced/Separated/Widowed & $174(87.4)$ & $6(13.9)$ & $9(12.7)$ & $10(11.8)$ \\
\hline \multicolumn{5}{|l|}{$\begin{array}{l}\text { HIV disclosure to } \\
\text { Casual Sex Partners }{ }^{\dagger}\end{array}$} \\
\hline Not Applicable & $31(15.6)$ & $6(14.0)$ & $13(18.3)$ & $12(14.1)$ \\
\hline None or hardly any & $23(11.6)$ & $5(11.6)$ & $13(18.3)$ & $5(5.9)$ \\
\hline Some & $32(16.1)$ & $7(16.3)$ & $9(12.7)$ & $16(18.8)$ \\
\hline Most or all & $105(52.7)$ & $24(55.8)$ & $31(43.7)$ & $50(58.8)$ \\
\hline Unknown & $8(4.0)$ & $1(2.3)$ & $5(7.0)$ & $2(2.4)$ \\
\hline
\end{tabular}

*Percentages are column percentages.

${ }^{\dagger}$ Missing HIV status disclosure for eight participants. 
Table 2. Sex at birth of Florida Cohort Study participants by specific venue where they met a new sexual partner, Florida, 2016*

\begin{tabular}{|l|c|c|c|}
\hline & $\begin{array}{c}\text { Total }^{\dagger} \\
(\mathrm{n}=199)\end{array}$ & $\begin{array}{c}\text { Male }^{\ddagger} \\
(\mathrm{n}=178)\end{array}$ & $\begin{array}{c}\text { Female }^{\ddagger} \\
(\mathrm{n}=21)\end{array}$ \\
\hline Specific venue & $n(\%)$ & $n(\%)$ & $n(\%)$ \\
\hline Work & $15(7.5)$ & $13(86.7)$ & $2(13.3)$ \\
\hline Through a friend $^{\S}$ & $86(43.2)$ & $72(83.7)$ & $14(16.3)$ \\
\hline Internet $^{\S}$ & $105(52.8)$ & $99(94.3)$ & $6(5.7)$ \\
\hline Bar or club $^{\S}$ & $85(42.7)$ & $82(96.5)$ & $3(3.5)$ \\
\hline Phone app (like Tinder or Grindr) $^{\S}$ & $82(41.2)$ & $80(97.6)$ & $2(2.4)$ \\
\hline Bath house $^{\S}$ & $45(22.6)$ & $45(100.0)$ & $0(0.0)$ \\
\hline Massage Parlor & $3(1.5)$ & $2(66.7)$ & $1(33.3)$ \\
\hline
\end{tabular}

*Participants had the option to select more than one venue.

${ }^{\dagger}$ Number and percentage of total population who reported a specific venue.

${ }^{\ddagger}$ Percentages are row percentages summing to the total number of people who reported a specific venue.

\$Statistically significant findings at $p \leq 0.05$ 
Table 3. Multivariate logistic regression results for "Technology-only" and "In-Person only" participants compared to "Technology \& In-Person" venue type, Florida, 2016.

\begin{tabular}{|c|c|c|}
\hline & $\begin{array}{c}\text { Technology only* } \\
(\mathrm{n}=43)\end{array}$ & $\begin{array}{c}\text { In-Person only* } \\
(\mathrm{n}=68)\end{array}$ \\
\hline & aOR $(95 \% C I)$ & aOR $(95 \% C I)$ \\
\hline \multicolumn{3}{|l|}{ Age } \\
\hline $18-24$ & $3.20(0.78-13.04)$ & $0.77(0.14-4.24)$ \\
\hline $25-29$ & $5.52(1.20-25.36)^{+}$ & $1.39(0.20-9.65)$ \\
\hline $30-39$ (ref) & - & - \\
\hline $40-49$ & $2.37(0.67-8.29)$ & $2.63(0.80-8.60)$ \\
\hline$\geq 50$ & $2.58(0.63-10.46)$ & $5.81(1.65-20.45)^{\dagger}$ \\
\hline \multicolumn{3}{|l|}{ Sex at Birth } \\
\hline Male & $0.17(0.01-2.08)$ & $0.42(0.06-2.61)$ \\
\hline Female (ref) & - & - \\
\hline \multicolumn{3}{|l|}{ Race/Ethnicity } \\
\hline Non-Hispanic White & $0.35(0.12-1.03)$ & $0.21(0.07-0.60)^{\dagger}$ \\
\hline Non-Hispanic Black (ref) & - & - \\
\hline Hispanic & $1.02(0.34-3.02)$ & $0.70(0.23-2.14)$ \\
\hline Other & $1.18(0.27-5.22)$ & $0.79(0.12-5.16)$ \\
\hline \multicolumn{3}{|l|}{ Education Level } \\
\hline High School or below (ref) & - & - \\
\hline Some college/tech/trade & $0.67(0.25-1.79)$ & $0.39(0.13-1.18)$ \\
\hline College/Trade school & $0.52(0.14-1.95)$ & $0.72(0.21-2.50)$ \\
\hline Graduate/Prof. degree & $1.41(0.30-6.62)$ & $0.84(0.16-4.25)$ \\
\hline \multicolumn{3}{|l|}{ Sexual Orientation } \\
\hline Heterosexual (ref) & - & - \\
\hline Gay or Lesbian & $0.98(0.15-6.19)$ & $0.10(0.02-0.41)^{\dagger}$ \\
\hline Bisexual & $2.53(0.27-23.65)$ & $0.87(0.14-5.20)$ \\
\hline \multicolumn{3}{|l|}{ Relationship Status } \\
\hline Married/Long-term partner (ref) & - & - \\
\hline Single/Divorced/Separated/Widowed & $1.36(0.37-4.96)$ & $2.17(0.56-8.39)$ \\
\hline
\end{tabular}

*Odds ratios are adjusted (aOR)

${ }^{\dagger}$ Statistically significant findings at $p \leq 0.05$ during multivariate logistic regression. 


\section{Manuscript 2}

(C) Copyright 2019

\section{Examining Venue Selection, Risky Sexual Behaviors, and Sexually Transmitted Diseases among persons living with HIV, Florida, 2014-2017}

\section{Abstract}

The purpose of this study was to examine how risky sexual behaviors and sexually transmitted disease prevalence varies among HIV-positive individuals by the venue type used to meet sexual partners. Two hundred and seventy-two persons living with HIV/AIDS (PLWHAs) were recruited from The Florida Cohort Study. Self-reported lifetime history of sexually transmitted disease and risky sexual behaviors reported by venue-type used to meet sexual partners ("Technology" vs. "Non-Technology") were examined using bivariate and multivariate logistic regression. Among 272 participants, 239 (87.8\%) were male, 129 (47.4\%) Non-Hispanic Black, and 148 (54.4\%) gay or lesbian. Significant differences were noted in demographics, STD history, and sexual partner type among "Technology" venues ( $\mathrm{n}=122)$ compared to "NonTechnology” venues ( $\mathrm{n}=150)$. “Technology” participants were more likely (aOR 2.32 [95\% CI $1.40-3.83])$ to report a history of syphilis in their lifetime $(n=71,59.2 \%)$ and unprotected sex $(\mathrm{n}=99,81.1 \%)(\mathrm{aOR} 2.42$ [95\% CI $1.37-4.25])$. Individuals meeting new sexual partners using "Technology" venues are more likely to report unprotected sex in the prior 12 months and a history of syphilis than individuals utilizing only "Non-Technology" methods. Based on the findings of this study, STD history and sexual behaviors may vary depending on venue type.

KEYWORDS: HIV, AIDS, Venue selection, Sexual Behaviors, Sexually Transmitted Diseases 
Introduction

Each year in the United States, 19 million people are diagnosed with a sexually transmitted disease (STD), costing the U.S. healthcare system 16 billion dollars annually (World Health Organization, 2015). According to the Florida Department of Health, the incidence of bacterial STDs has increased from 425.3 per 100,000 persons per year in 2006 to 684.7 per 100,000 persons per year in 2017 (Florida Charts, 2018). This rise in STDs has increased concomitantly with advancing technology, starting with at-home Internet in the early 1990s to the introduction of social networking smartphone applications (SNSA) on mobile Smartphones in the late 2000s (Grov et al., 2011; Klausner et al., 2011; Winetrobe et al., 2014). To date, limited research has been conducted examining the association between risky sexual behaviors, STDs, and venue where an individual meets sexual partners, especially comparing use of technology (the internet, SNSA or mobile apps, etc.) venues to meet sexual partners to other venues (bar, club, bathhouse, etc.).

Risks associated with the Internet and SNSAs have been well established within menwho-have-sex-with-men (MSM) populations. Research has documented a higher number of sexual partners, unprotected sexual acts, consumption of alcohol in conjunction with sexual activity, more sexually transmitted infections among these Internet and SNSA users (McFarlane et al., 2000; Seal et al., 2015; Benostch et al., 2011; Bull et al., 2000; Garofalo et al., 2007; Horvath et al., 2006; McFarlane et al., 2002; McKirnan et al., 2007; Davis et al., 2006; Landovitz et al., 2013; Lehmiller et al., 2014). Studies suggest that SNSA users were more likely to report an STD than non-SNSA users (Lehmiller et al., 2014; Beymer et al. 2014). Virtual platforms such as SNSAs allow for the social networking of individuals who may not meet via other 
venues, a phenomenon which may increase the likelihood of contracting an STD through access to multiple sexual partners.

In-person venues (such as bars, clubs, or bathhouses) continue to provide environments where risky sexual behaviors are facilitated (Mayer et al., 2012; Binson et al., 2010; Schrimshaw et al., 2013). Venue type selection may vary depending on whether individuals are trying to be discrete in finding new sexual partners. Meeting in parks and public restrooms are frequently reported among MSM-who-have-sex-with-women (MSMW) who are hiding their same-sex partnerships from their female partners (Schrimshaw et al., 2013). Social norms within each venue can play a role in how MSM negotiate HIV-associated risk behaviors, such as serostatus disclosure and condom use (Binson et al., 2010). Studies have noted that HIV status disclosure was lowest among men who met their most recent partner in a park, outdoors, or other public place and highest among men who met their most recent partner online (Schrimshaw et al., 2013; Grov et al., 2013).

Limited research has been conducted among women and racial minority groups; however, available research suggests that both women and Hispanic MSM also engage in risky behaviors with the Internet. A survey found that $43 \%$ of adult women reported having sex with a person they first met on the Internet (McFarlane et al., 2004). These women were also found to have higher self-reported rates of STDs, inconsistent condom usage, and reported engaging in anal, oral, and vaginal sex with Internet partners (McFarlane et al., 2004). Overall, there are many risks associated with "swiping-right"- - but these risks have yet to be examined among women, lower-income users of both apps and the Internet, people living with HIV, and racial/ethnic minorities. 


\section{Purpose of the Study}

The purpose of this study was to determine whether venue type used to meet sexual partners was associated with risky sexual behaviors and lifetime history of sexually transmitted disease among persons living with HIV in Florida. This study examined whether individuals living with HIV reporting "Technology" venues to meet new sexual partners are more likely to report risky sexual behaviors and a history of sexually transmitted diseases compared to individuals who met new sexual partners via only "Non-Technology" venues. We hypothesize that those who meet new sexual partners via technology venues would report more sexual risk behaviors and history of sexually transmitted diseases.

Methods

Study Population

Between October 2014 and September 2017, 932 persons living with HIV/AIDS (PLWHA) were recruited into the Florida Cohort Study (FCS). The Florida Cohort Study recruited from a collaborative network of county health department and community clinics, and settings throughout Florida, including sites at Lake City, Gainesville, Tampa, Orlando, Sanford, Ft. Lauderdale, and Miami. Inclusion criteria for the study include being over the age of 18, HIV positive, and living in the state of Florida. After written informed consent was obtained, participants completed a Research Electronic Data Capture (REDCap®) survey in English or Spanish. Surveys took approximately 30-45 minutes to complete, and participants were provided a \$25 gift card upon completion (Ibanez et al., under review; Lucero et al., 2017; Sharpe et al., 2018). The cross-sectional survey asked participants questions about their demographics, how 
they met new sexual partners in the past 12 months (defined in this study as venue), and their sexual history. The Florida Cohort Study was approved by Institutional Review Boards (IRBs) at the University of Florida, Florida International University, and the Florida Department of Health; and this research study was approved by Florida International University’s IRB.

\section{Measures}

For this study, we conducted a secondary data analysis of baseline data collected from the Florida Cohort Study. Demographic variables of interest included age (in years), age-group (1829, 30-39, 40-49, $\geq 50$ ), sex at birth (male or female), race/ethnicity (Non-Hispanic White, NonHispanic Black, Hispanic, Other), education level (high school or below, some college or some tech/trade school, college/trade school, or graduate degree/professional degree), self-reported sexual orientation (heterosexual or gay/lesbian/bisexual), and relationship status (single vs. nonsingle).

Venue-type was determined based on how participants responded to locations where they had met new sexual partners in the prior 12 months (internet, phone app [like Tinder or Grindr], bar or club, bathhouse, massage parlor, work, and/or friend, and other) (SHARC). Given small samples sizes for some locations, individual venues were grouped into venue-types:

"Technology" (any Internet and/or SNSAs) or "Non-Technology" (only bar or club, bathhouse, massage parlor, work, and/or friend, and/or other). The Florida Cohort Study did not ask for additional information concerning "other"; however, due to the exhaustive list of "technology" options it is believed that the "other" venue is a "Non-Technology" venue. 
Risky sexual behaviors included a self-reported categorical range of sexual partners in the previous 12 months (None, $<5, \geq 5$ ), number of unprotected sex partners in the previous 12 months (None, , $<5, \geq 5$ ), and gender of sexual partners during the past 12 months. The number of unprotected sex partners was further reclassified, as a binary variable (i.e. "yes" [ $\geq 1$ partners] vs "no" [0 partners]), as having reported unprotected sex in the previous 12 months. Participants were also asked whether they had sex with partners having specific characteristics in the previous 12 months (i.e. partner met on the internet or cell phone application, partner with HIV, partner without HIV, an anonymous sex partner). For each partner type, the participant indicated whether they "always" or "did not always" use condoms with these individuals. Sexually transmitted disease included self-reported history of chlamydia, syphilis, genital herpes, and genital warts which was reclassified as a binary variable (i.e. "never" vs. "ever”).

\section{Data Analysis Plan}

In order to examine the role of venue type in risky sexual behavior and STDs, we used the following strategy. Descriptive statistics (frequencies, chi-square and fisher tests) were conducted to examine demographics and sexual behavior characteristics by venue-type (technology/non-technology) in which participants met partners. We then used logistic regression to determine factors that are associated with venue type, using an alpha of 0.05 , in order to determine covariates to include in the model. Lastly, we conducted multivariate logistic regression to determine if venue type was a predictor for risky sexual behavior (unprotected sex) and STD infection (history of syphilis), adjusting for demographic and sexual risk covariates. Data concerning other STDs is presented in the tables but was not included in analysis due to small sample size. All covariates significantly associated with venue type were included in the 
model. A backward selection modelling strategy was used to arrive at a parsimonious model. Separate sub-analyses examined risk covariates among female participants. All statistical analyses were performed using SAS software, version 9.4.

Results

Demographics of Study Population

Among the 932 respondents, 660 were excluded from analysis. Individuals who reported not having sex in the prior 12 months $(n=275)$, not meeting a new sexual partner in the prior 12 months $(n=333)$, or not reporting a venue where they had met a new sexual partner $(n=52)$ were excluded from the analysis. Among the 272 participants included in the analyses, $122(44.8 \%)$ reported "Technology" venues and 150 (55.2\%) "Non-Technology” venues. Demographic characteristics of the 272 participants meeting the inclusion criteria are presented in Table 1. For this analysis, participants who responded "Other" as a venue were included in the sample. Most participants were male $(n=239,87.9 \%)$, over the age of forty $(n=166,61.0 \%)$ with median age of 45 years (range $19-68)$, and Non-Hispanic Black/African American $(n=129,47.4 \%)$. Univariate analysis found that age, sex at birth, race/ethnicity, education level, sexual orientation, and gender of sexual partner were found to be associated with venue type $(p \leq 0.05)$ and included in multivariate analysis (Table 1). Relationship status was not associated with venue type $(\mathrm{p}<0.31)$ (see Table 1). In addition, 109 (89.3\%) of “Technology” participants reported having sex with men only in the prior 12 months compared to only $82(55.4 \%)$ of "Non-Technology" participants. 
Among thirty-two females, $29(90.6 \%)$ reported having sex with men-only in the prior 12 months. Twenty-seven $(81.8 \%)$ women reported being heterosexual. Among the thirty-three females, only $5(15.1 \%)$ reported meeting recent sexual partners using "Technology" based methods. All five of those women were between the ages of 30 to 49 years old, reported being heterosexual, and did not report having an anonymous sex partner. However, due to small sample sizes by venue type, we were unable to determine whether there were differences in age, race/ethnicity, sexual orientation, and gender of sexual partner by venue type among female participants.

\section{Risky Sexual Behaviors}

Among individuals reporting unprotected sex, 173 (64.0\%) reported between one and four sexual partners in the prior 12 months and 97 (36.0\%) reported more than five sexual partners. Twenty-seven $(9.9 \%)$ reported more than 10 unprotected sexual partners in the previous 12 months. "Technology" participants were more likely to report more than five sexual partners in the prior 12 months and unprotected sex in the prior 12 months than "Non-Technology" participants (Table 2).

HIV status disclosure also differed between "Technology” \& "Non-Technology" venues (see Table 2). "Non-technology" participants were 3.13 times more likely to report disclosing their HIV status to "none or hardly any" of their sexual partners compared to disclosing "Technology" participants in unadjusted models. During the multivariate analysis, having an HIV positive partner and having an anonymous sex partner were associated with engaging in unprotected sex (see Table 3). 


\section{Sexually Transmitted Diseases}

Among the 272 participants, individuals who met a new sexual partner in the prior 12 months, 89 (73.5\%) of "Technology" participants and 94 (64.4\%) of "Non-Technology" participants, reported ever having an STD $(\mathrm{p}<0.1082)$. Of these participants who reported an STD in the previous 12 months, 40 (14.8\%) reported chlamydia, 49 (18.0\%) syphilis, 17 (6.3\%) genital herpes, and $13(4.8 \%)$ genital warts. Overall, $183(62.7 \%)$ reported a history of any STD in their lifetime. Among the thirty-three female participants, 23 (69.7\%) reported ever having an STD. There were no statistically significant differences between "Technology" and "NonTechnology" participants in reported history of any STD, chlamydia, genital herpes, and genital warts (Table 2). However, there was a statistically significant difference for syphilis $(\mathrm{p}<0.0009)$ in which $59.2 \%$ of "Technology" participants reported a lifetime history of syphilis compared to $38.4 \%$ of "Non-Technology" participants. During multivariate analysis only having more than five sexual partners in the prior 12 months was associated with reporting a history of syphilis (aOR 2.20 [95\% CI $1.18-4.11]$ ) (Table 4).

Discussion

This study is one of the first to examine risky sexual behaviors and STD history among a diverse sample of PLWHAs in the state of Florida by the venue-types where they met new sexual partners. This is also a sample that was not recruited using venue-based sampling, and examined STD history by venue type within a small population of HIV positive heterosexual women. Overall, this study found that participants who utilized "Technology" venues were significantly more likely to report a previous history of syphilis and report unprotected sex. The study also 
found that participants who reported engaging in unprotected sex were more likely to report sexual partners who were anonymous and living with HIV/AIDS.

\section{Syphilis and Sexual Partners}

Among PLWHAs, individuals who have a higher number of sexual partners were more likely to report a history of syphilis. This finding identified a clearer link between technology, the number of sexual partners, and syphilis, but did not find similar associations with other STDs (Lehmiller et al., 2014; Beymer et al., 2014). A study by Zetola et al., found that one-fourth of HIV-infected patients present with syphilis at the time of HIV diagnosis (Zetola et al., 2007). However, future studies should examine whether incidence of syphilis is higher among individuals living with HIV compared to seronegative populations. Of note, among female participants, reporting a history of syphilis was associated with having more than five sexual partners in the prior 12 months. This is consistent with the previously mentioned literature conducted among MSM which show that STD risk increases with more sexual partners (Lehmiller et al., 2014; Beymer et al., 2014; Mayer et al., 2012). However, these results describing the female cohort, while limited by a small sample size which prevented any multivariate analysis, are the first findings to describe venue type among women living with HIV. In addition, a study found a similar association with lifetime number of sexual partners and reporting a history of syphilis, also among MSM (Gallo et al., 2012). Future studies should recruit women living with HIV with a sample size of appropriate power to further examine this putative association and fill gaps in knowledge concerning how women living with HIV meet new sexual partners. 


\section{Unprotected Sex and Sexual Partners}

An interesting finding is that PLWHA who have a sexual partner with HIV/AIDS or an anonymous sex partner may be more likely to engage in unprotected sex. The finding that participants reporting unprotected sex were more likely to have a sexual partner with HIV/AIDS suggests that serosorting (i.e. intentionally seeking a partner who has HIV) may be occurring within this population (Grov et al., 2013). Among Florida Cohort Study participants who reported engaging in anonymous sex, most participants reported disclosing their HIV status to casual sex partners in the prior 12 months. As such, despite the anonymity associated with many technology-based venues, HIV status disclosure was significantly lower within "non-technology" venues. This finding may be due to the face to face nature of these venue types compared to technology venues, where modern dating apps allow for HIV status disclosure on a user's profile. In fact, a study by Medina et al., found that 55\% of MSM in the study disclosed their HIV status using the app profile options to disclose status (Medina et al., 2018). Studies have also noted that HIV status disclosure was lowest among men who met their most recent partner in a park, outdoors, or other public place and highest among men who met their most recent partner online (Schrimshaw et al., 2013; Grov et al., 2013). This difference may be due to a an individual's fear of stigma or rejection due to their HIV status. Lastly, limited research has been conducted to specifically examine the role of serosorting and venue type, multiple studies have noted that HIV status is often disclosed on SNSA and Internet user profiles which suggests that users may use this information for the purposes of serosorting (Binson et al., 2010; Grov et al., 2013). Future studies, perhaps qualitative studies, should further examine serosorting behaviors within this context as our findings do suggest that venue type may facilitate serosorting among this cohort and to inform future health education campaigns promoting safe serosorting practices. 


\section{Co-infections with other STDs}

The study also identified a high burden of STDs among participants, specifically syphilis. To date, only one study has examined STI incidence among HIV positive individuals in Florida. This study of 175 patients visiting an STD clinic in Miami-Dade County found that an acute infection with Syphilis was more likely to be associated with being HIV positive (Castro et al., 2016). In fact, $29 \%$ of Miami-Dade patients were diagnosed with syphilis at the time of their visit and $75 \%$ reported a history of STDs. This is consistent with our finding that almost half our sample had a self-reported history of syphilis. Moreover, our study puts it in the context of venue type. Future studies should examine factors associated with co-infection of STDs among this cohort to determine whether education or interventions could be designed prevent the spread of future STIs and HIV within this relatively risky cohort population by targeting these populations at venues.

\section{Social Media Interventions}

As access to the Internet is expanding through smartphones and tablets, this technology may serve as a venue for STD health education in promoting sexual health (Gabarron et al., 2016; Jones et al., 2012). Lucero et al. found that among the Florida Cohort Study respondents, 85.5\% were interested in using a free mobile phone app that supports HIV self-management (Lucero et al., 2017). There are many opportunities to use the information gained from this study to create "Swipe Smart" interventions with the potential to target high-risk individuals who use multiple technology-based and in-person methods to meet new sexual partners, through pushnotifications of safe sex messaging and STD clinics near them. 
There are several limitations identified in this study. Due to the inclusion criteria of this study, most of the original sample was excluded from analysis, and as such, our finding that almost half of participants reported a previous history of syphilis may be due to our selection criteria of only including individuals who met new sexual partners in the prior 12 months. In addition, due to the self-report nature of the survey there may be social desirability bias in the reporting of venues, especially disclosure of utilizing bathhouses to meet sexual partners, and self-reporting STD history. Furthermore, a participant using both "Technology" and "NonTechnology" methods fell into the "Technology" category, which may bias the "Technology" findings. Lastly, while our study did not examine compounding risks associated with utilizing multiple venues, our findings suggest that PLWHAs utilize multiple venue types to meet new sexual partners. In fact, a 2013 study found that most of their participants met all of their recent sexual partners through a single venue (Liau et al., 2006). However, this study did not examine whether risk increased with multiple venues, nor did it assess whether risks varied depending of the type of internet (i.e. websites vs. apps). Lastly, this study examined risk factors in the prior 12 months with an outcome of reporting lifetime history of STDs, due to the small sample size of individuals reporting recent STIs during the prior 12 months.

Overall, this study has notable strengths. The Florida Cohort Study aimed to be representative of PLWHA in the state of Florida; this report provides a much-needed representation concerning the role of venue type selection among PLWHAs in Florida and likely can be generalizable to most cohorts of PLWHAs. This is the first study, to our knowledge, to examine PLWHA's sexually transmitted disease history and risky sexual behaviors by location of meeting sexual partners, and the role of reporting multiple venue types. In addition, this was 
the first study to examine these topics within an ethnically diverse, middle-aged cohort of persons living with HIV/AIDs recruited from clinics throughout the state of Florida.

\section{Conclusions}

Prior to this study, whether reporting a recent STD and/or riskier sexual behaviors were more likely among those meeting new partners in technology-based venue types compared to non-technology-based venues were largely unknown, particularly within non-MSM populations. Based on the findings of this study, STD history and sexual behaviors may vary depending on venue type for meeting sexual partners; however, models suggest other factors play a role in engaging in risky behaviors and likelihood of reporting a STD. Future studies should include the expansion of the Florida Cohort Study to include HIV negative participants, particularly females, to examine how venue type selection varies by HIV status and gender.

\section{REFERENCES}

Benotsch E, Martin A, Espil F, et al. "Internet use, recreational travel, and HIV risk behaviors in men who have sex with men.” 2011. J Comm Health. 36(3):398-405.

Beymer M, Weiss R, Bolan R, et al. "Sex on demand: Geosocial networking phone apps and risk of sexually transmitted infections among a cross-sectional sample of men who have sex with men in Los Angeles county." 2014. Sex Transm Infect. 90(7): 567-572.

Binson D, Pollack L, Blair J, et al. "HIV transmission risk at a gay bathhouse." 2010. J Sex Res. 47(6): 580-588.

Bull S, McFarlane M. "Soliciting sex on the Internet - what are the risks for sexually transmitted diseases and HIV." 2000. J Sex Transm Dis. 27(9): 545-550.

Castro J, Alcaide M. "High Rates of STIs in HIV-infected Patients Attending an STI Clinic." 2016. South Med J. 10(1):1-4.

Davis M, Hart G, Bolding G, et al. "Sex and the Internet: Gay men, risk reduction and serostatus." 2006. Cult Health Sex. 8(2):161-174. 
Florida Charts. Total Bacterial STDs. Florida Department of Health, Bureau of Communicable Diseases. 2018. Available at:

http://www.flhealthcharts.com/charts/OtherIndicators/NonVitalSTDDataViewer.aspx?cid=9767. Accessed July 5, 2018.

Gabarron E, Wynn R. "Use of Social Media for Sexual Health Promotion: a scoping review." 2016. Glob Health Action. 9:e32193.

Gallo M, Macaluso M, Warner L, et al. "Bacterial Vaginosis, Gonorrhea, and Chlamydial Infection Among Women Attending a Sexually Transmitted Disease Clinic: A Longitudinal Analysis of Possible Causal Links." 2012. Ann Epidemiol. 22(3):213-300.

Garofalo R, Herrick A, Mustanski B, et al. "Tip of the iceberg: Young men who have sex with men, the Internet, and HIV risk.” 2007. Am J Public Health Res. (97):1113-1117.

Grov C, Hirshfield S, Remien R, et al. "Exploring the Venue: Role in Risky Sexual Behavior Among Gay and Bisexual Men: An Event-Level Analysis from a National Online Survey in the U.S.” 2011. Arch Sex Behav. 42 (2): 291-302.

Grov C, Agyemang L, Ventuneac A, et al. "Navigating condom use and HIV status disclosure with partners met online: A qualitative pilot study with gay and bisexual men from Craigslist.com.” 2013. AIDS Educ Prev. 25 (1): 72-85.

Horvath K, Bowen A, Williams M. "Virtual and physical venues as contexts for HIV risk among rural men who have sex with men." 2006. Health Psychol. (25): 237-242.

Ibanez G, Zhou Z, Cook C, et al. "The Florida Cohort Study: Methodological challenges and lessons learned in the design and implementation of a new cohort of persons living with HIV (PLWH)." Under review.

Jones K, Baldwin K, Lewis P. "The potential influence of a social media intervention on risky sexual behavior and chlamydia incidence.” 2012. J Community Health Nurs. 29(2): 106-120.

Klausner J. "Chapter 13: Tracking a Syphilis Outbreak Through Cyberspace. In: Dworkin M. Cases in Field Epidemiology." 2011. A Global Perspective. Sudbury, MA. Jones \& Bartlett Learning. (13): 163-71.

Landovitz R Tseng C, Weissman M, et al. "Epidemiology, Sexual Risk Behavior, and HIV Prevention Practices of Men who have Sex with Men Using GRINDR in Los Angeles, California." 2013. J Urban Health. 90(4): 729-739.

Lehmiller J, Joerger M. "Social networking Smartphone applications and sexual health outcomes among men who have sex with men.” 2014. PloS One. 9(1): e86603.

Liau A, Millett G, Marks G. "Meta-analytic examination of online sex seeking and sexual risk behavior among men who have sex with men." 2006. Sexually Trans Dis. 33(9):576-584

Lucero R, Frimpong J, Fehlberg E, et al. "The Relationship Between Individual Characteristics and Interest in Using a Mobile Phone App for HIV Self-Management: Observational Cohort Study of People Living with HIV." 2017. JMIR. 5(7):100. 
Mayer K, Ducharme R, Zaller N, et al. "Unprotected Sex, Underestimated Risk, Undiagnosed HIV and Sexually Transmitted Diseases Among Men Who Have Sex With Men Accessing Testing Services in a New England Bathhouse." 2012. J Acquir Immune Defic Syndr. 59 (2): 194-198.

McFarlane M, Bull S, Rietmeijer C. "The Internet as a newly emerging risk environment for sexually transmitted diseases.” 2000. JAMA. 284(4): 443-446.

McFarlane M, Bull SS, Rietmeijer CA, et al. "Young adults on the Internet: Risk behaviors for sexually transmitted diseases and HIV.” 2002. J Adolesc Health. (31): 11-16.

McFarlane M, Kachur R, Bull S, et al. "Women, the Internet, and Sexually Transmitted Infections.” 2004. Journal of Women's Health. 13 (6): 689-694.

McKirnan D, Houston E, Tolou-Shams M. "Is the Web the culprit? Cognitive escape and Internet sexual risk among gay and bisexual men.” 2007. AIDS Behav. (11): 151-160.

Medina M, Crowley C, Montgomery M, et al. "Disclosure of HIV Serostatus and Pre-exposure Prophylaxis Use on Internet Hookup Sites Among Men Who Have Sex with Men.” 2018. AIDS Behav. 23(7):1681-1688.

Schrimshaw E, Downing M, Siegel K, et al. "Sexual Venue Selection and Strategies for Concealment of Same-Sex Behavior Among Non-Disclosing Men Who Have Sex with Men and Women.” 2013. J Homosex. 60 (1): 120-145.

Seal D, Benotsch E, Green M, et al. "The use of internet chat rooms to meet sexual partners: A comparison of non-heterosexually identified men with heterosexually identified men and women.” 2015. Int J Sex Health. 27(1):1-15.

SHARC Questionnaire. Southern HIV and Alcohol Research Consortium (SHARC). University of Florida. Available at: http://sharc-research.org/wpcontent/uploads/2017/07/Phase1_Orange_bs_v2_120314.pdf. Accessed August 24, 2017.

Sharpe J, Zhou Z, Escobar-Viera C, et al. "Interest in using mobile technology to help selfmanage alcohol use among persons living with the human immunodeficiency virus: A Florida Cohort cross-sectional study." 2018. Subst Abus. 39 (1): 77-82.

Winetrobe H, Rice E, Bauermeister J, et al. "Associations of Unprotected Anal Intercourse with Grindr-met Partners among Grindr-using Young Men Who Have Sex with Men in Los Angeles." 2014. AIDS Care. 26(10): 1303-308.

World Health Organization.

Global Estimates Shed Light on Toll of Sexually Transmitted Infections." 2015. Available at: http://www.who.int/reproductivehealth/news/stis-estimates-2015/en/. Accessed July 5, 2018.

Zetola N, Klausner J. "Syphilis and HIV Infection: An Update." 2007. Clin Infect Dis. 44 (9): 1222-1228. 
Table 1. Demographics characteristics of Florida Cohort Study Participants using Technology vs. Non-Technology venue types, Florida, 2014-2017.

\begin{tabular}{|c|c|c|c|}
\hline & $\begin{array}{l}\text { Technology } \\
(\mathrm{n}=122)\end{array}$ & $\begin{array}{c}\text { Non-Technology } \\
(\mathrm{n}=150)\end{array}$ & \\
\hline Demographic variables & $n(\%)$ & $n(\%)$ & $P$-value \\
\hline Age & & & $<0.0001$ \\
\hline $18-29$ & $33(27.0)$ & $14(9.3)$ & \\
\hline $30-39$ & $29(23.8)$ & $30(20.0)$ & \\
\hline $40-49$ & $37(30.3)$ & $35(23.3)$ & \\
\hline$\geq 50$ & $23(18.9)$ & $71(47.4)$ & \\
\hline Sex at Birth & & & 0.0003 \\
\hline Male & $117(95.9)$ & $122(81.3)$ & \\
\hline Female & $5(4.1)$ & $28(18.7)$ & \\
\hline Race/Ethnicity & & & $<0.0001$ \\
\hline Non-Hispanic White & $44(36.0)$ & $23(15.3)$ & \\
\hline Non-Hispanic Black & $38(31.2)$ & $91(60.7)$ & \\
\hline Hispanic & $28(23.0)$ & $32(21.3)$ & \\
\hline Other & $12(9.8)$ & $4(2.7)$ & \\
\hline Education Level & & & 0.0001 \\
\hline High School or below & $48(39.4)$ & $92(64.3)$ & \\
\hline Some college/tech/trade & $44(26.0)$ & $25(17.5)$ & \\
\hline College/Graduate School & $30(24.6)$ & $26(18.2)$ & \\
\hline \multicolumn{4}{|l|}{ Sexual Orientation } \\
\hline Heterosexual & $10(8.4)$ & $73(49.3)$ & $<0.0001$ \\
\hline $\begin{array}{c}\text { Gay or Lesbian, Bisexual, } \\
\text { Asexual, \& Other }\end{array}$ & $110(91.6)$ & $75(50.7)$ & \\
\hline Gender of Sexual Partners & & & $<0.0001$ \\
\hline Men only & $109(89.3)$ & $82(55.4)$ & \\
\hline Women only & $4(3.3)$ & $46(31.1)$ & \\
\hline Men \& Women & $9(7.4)$ & $20(13.5)$ & \\
\hline Relationship Status & & & 0.3113 \\
\hline Single/Divorced & $107(87.7)$ & $125(83.3)$ & \\
\hline Married/Long-term partner & $15(12.3)$ & $25(16.7)$ & \\
\hline
\end{tabular}


Table 2. Differences in sexual behavior and outcomes of persons living with HIV who met new sexual partners using Technology vs. only Non-Technology venue types, Florida, 20142017.

\begin{tabular}{|c|c|c|c|}
\hline & $\begin{array}{c}\text { Technology } \\
(\mathrm{n}=122)\end{array}$ & $\begin{array}{c}\text { Non-Technology } \\
(\mathrm{n}=150)\end{array}$ & \\
\hline & $n(\%)$ & $n(\%)$, & $P$-values \\
\hline Number of Sexual Partners in the prior 12 months & & & $<0.0001$ \\
\hline $1-4$ & $59(48.4)$ & $114(77.0)$ & \\
\hline$\geq 5$ & $63(51.6)$ & $34(23.0)$ & \\
\hline \multicolumn{4}{|l|}{ Unprotected Sex in Prior 12 months } \\
\hline No & $23(18.9)$ & $54(36.0)$ & 0.0018 \\
\hline Yes & $99(81.1)$ & $96(64.0)$ & \\
\hline Previous History of a Sexually Transmitted Disease & & & 0.1082 \\
\hline Never & $32(26.5)$ & $52(35.6)$ & \\
\hline Ever & $89(73.5)$ & $94(64.4)$ & \\
\hline Chlamydia & & & 0.1408 \\
\hline Never & $56(47.9)$ & $81(57.0)$ & \\
\hline Ever & $61(52.1)$ & $61(43.0)$ & \\
\hline Syphilis & & & 0.0009 \\
\hline Never & $49(40.8)$ & $85(61.6)$ & \\
\hline Ever & $71(59.2)$ & $53(38.4)$ & \\
\hline Genital Herpes & & & 0.9363 \\
\hline Never & $95(82.6)$ & $111(82.2)$ & \\
\hline Ever & $20(17.4)$ & $24(17.8)$ & \\
\hline Genital Warts & & & 0.9341 \\
\hline Never & $99(85.3)$ & $114(85.7)$ & \\
\hline Ever & $17(14.7)$ & $19(14.3)$ & \\
\hline \multicolumn{4}{|l|}{ Have you had a sexual partner... } \\
\hline .... who was HIV positive in the prior 12 months? & & & $<0.0001$ \\
\hline No & $25(20.7)$ & $69(47.6)$ & \\
\hline Yes & $96(79.3)$ & $76(52.4)$ & \\
\hline .... who was HIV negative in the prior 12 months? & & & $\mathbf{0 . 0 2 3 1}$ \\
\hline No & $26(22.0)$ & $50(35.0)$ & \\
\hline Yes & $92(78.0)$ & $93(65.0)$ & \\
\hline ... whom you did not know (anonymous sex) or someone you just met? & & & $<0.0001$ \\
\hline No & $36(27.8)$ & $80(57.1)$ & \\
\hline Yes & $85(70.2)$ & $60(42.9)$ & \\
\hline Disclosed HIV Status to Casual Sex Partners & & & 0.0115 \\
\hline Not applicable & $18(15.1)$ & $27(19.0)$ & \\
\hline Most or all/Some & $92(77.3)$ & $88(62.0)$ & \\
\hline None or hardly any & $9(7.6)$ & $27(19.0)$ & \\
\hline
\end{tabular}


Table 3. Unadjusted and adjusted analyses of Unprotected Sex among Florida Cohort Study participants, Florida, 2014-2017.

\begin{tabular}{|c|c|c|c|c|}
\hline & $\begin{array}{c}\text { Bivariate } \\
\text { Odds Ratio }(95 \% \mathrm{CI})\end{array}$ & $P$-value & $\begin{array}{c}\text { Multivariate } \\
\text { Odds Ratio }(95 \% \text { CI) }\end{array}$ & $P$-value \\
\hline Venue Type & & 0.0021 & & 0.6384 \\
\hline Technology & $2.42(95 \%$ CI $1.37-4.25)$ & 0.0021 & $0.83(95 \%$ CI $0.38-1.78)$ & 0.6384 \\
\hline Non-Technology & ref & & ref & \\
\hline Age & & 0.0782 & & \\
\hline $18-29$ & $2.50(95 \%$ CI $1.08-5.79)$ & 0.0318 & & \\
\hline $30-39$ & $1.46(95 \%$ CI $0.72-2.95)$ & 0.2856 & & \\
\hline $40-49$ & $2.07(95 \%$ CI $1.03-4.16)$ & 0.0395 & & \\
\hline$\geq 50$ & ref & & & \\
\hline Sex at Birth & & 0.0584 & & \\
\hline Male & $2.05(95 \%$ CI $0.97-4.35)$ & 0.0584 & & \\
\hline Female & ref & & & \\
\hline Race/Ethnicity & & 0.0164 & & 0.0777 \\
\hline Non-Hispanic White & $2.91(95 \%$ CI $1.39-6.11)$ & 0.0045 & $2.22(95 \%$ CI $0.92-5.35)$ & 0.0736 \\
\hline Non-Hispanic Black & ref & & ref & \\
\hline Hispanic & $1.45(95 \%$ CI $0.74-2.82)$ & 0.2746 & $0.79(95 \%$ CI $0.34-1.82)$ & 0.5894 \\
\hline Other & $4.01(95 \%$ CI $0.87-18.42)$ & 0.0741 & $6.46(95 \%$ CI $0.71-58.07)$ & 0.0957 \\
\hline Education Level & & 0.1500 & & \\
\hline High School or below & ref & & & \\
\hline Some college/tech/trade & $1.86(95 \%$ CI $0.93-3.69)$ & 0.759 & & \\
\hline College/Graduate School & $1.56(95 \%$ CI $0.76-3.20)$ & 0.2181 & & \\
\hline Sexual Orientation & & $<0.0001$ & & 0.1618 \\
\hline Heterosexual & ref & & ref & \\
\hline $\begin{array}{l}\text { Gay or Lesbian, Bisexual, } \\
\text { Asexual \& Other }\end{array}$ & $3.11(95 \%$ CI $1.77-5.45)$ & $<0.0001$ & $1.83(95 \%$ CI $0.78-4.31)$ & 0.1618 \\
\hline Gender of Sexual Partners & & 0.0022 & & 0.2034 \\
\hline Men only & ref & & ref & \\
\hline Women only & $0.31(95 \%$ CI $0.16-0.60)$ & 0.0005 & $0.88(95 \%$ CI $0.33-2.34)$ & 0.8065 \\
\hline Men \& Women & $0.64(95 \%$ CI $0.27-1.52)$ & 0.3171 & $0.38(95 \%$ CI $0.13-1.10)$ & 0.0750 \\
\hline Relationship Status & & 0.2105 & & \\
\hline Married/Long-term partner & $1.69(95 \%$ CI $0.74-3.86)$ & 0.2105 & & \\
\hline Single/Divorced & ref & & & \\
\hline $\begin{array}{l}\text { Number of Sexual Partners in the } \\
\text { prior } 12 \text { months }\end{array}$ & & $<0.0001$ & & 0.0774 \\
\hline $1-4$ & ref & & ref & \\
\hline$\geq 5$ & $3.79(95 \%$ CI $1.95-7.34)$ & $<0.0001$ & $2.13(95 \%$ CI $0.92-4.93)$ & 0.0774 \\
\hline \multicolumn{5}{|l|}{ Have you had a sexual partner... } \\
\hline $\begin{array}{l}\text {... who was HIV positive in the prior } \\
12 \text { months? }\end{array}$ & & $<0.0001$ & & 0.0128 \\
\hline No & ref & & ref & \\
\hline Yes & $3.82(95 \%$ CI $2.17-6.73)$ & $<0.0001$ & $2.39(95 \%$ CI $1.20-4.74)$ & 0.0128 \\
\hline $\begin{array}{l}\text {... who was HIV negative in the prior } \\
12 \text { months? }\end{array}$ & & 0.5354 & & \\
\hline No & ref & & & \\
\hline Yes & $1.20(95 \%$ CI $0.66-2.16)$ & 0.5354 & & \\
\hline
\end{tabular}




\begin{tabular}{|l|c|c|c|c|}
\hline $\begin{array}{l}\ldots \text { whom you did not know (anonymous } \\
\text { sex) or someone you just met? }\end{array}$ & & $<\mathbf{0 . 0 0 0 1}$ & $\mathbf{0 . 0 0 0 9}$ \\
\hline No & ref & & ref & \\
\hline Yes & $5.07(95 \%$ CI $2.79-9.22)$ & $<\mathbf{0 . 0 0 0 1}$ & $3.28(95 \%$ CI $1.63-6.61)$ & $\mathbf{0 . 0 0 0 9}$ \\
\hline & & & & \\
\hline $\begin{array}{l}\text { Disclosed HIV Status to Casual Sex } \\
\text { Partners }\end{array}$ & & 0.6982 & & \\
\hline Not applicable & ref & & & \\
\hline Most or all/Some & $0.80(95 \%$ CI $0.37-1.75)$ & 0.5921 & & \\
\hline None or hardly any & $0.64(95 \%$ CI $0.23-1.76)$ & 0.3966 & & \\
\hline
\end{tabular}


Table 4. Unadjusted and Adjusted analyses of Syphilis infection among Florida Cohort Study participants, Florida, 2014-2017.

\begin{tabular}{|c|c|c|c|c|}
\hline & $\begin{array}{c}\text { Bivariate } \\
\text { Odds Ratio }(95 \% \text { CI) }\end{array}$ & $P$-value & $\begin{array}{c}\text { Multivariate } \\
\text { Odds Ratio }(95 \% \mathrm{CI})\end{array}$ & $P$-value \\
\hline Venue Type & & 0.0010 & & \\
\hline Technology & $2.32(95 \%$ CI $1.40-3.83)$ & 0.0010 & $1.19(95 \%$ CI $0.63-2.23)$ & 0.5877 \\
\hline Non-Technology & ref & & ref & \\
\hline Age & & 0.4867 & & \\
\hline $18-29$ & $1.14(95 \%$ CI $0.55-2.35)$ & 0.7162 & & \\
\hline $30-39$ & $1.62(95 \%$ CI $0.82-3.19)$ & 0.1603 & & \\
\hline $40-49$ & $1.44(95 \%$ CI $0.76-2.72)$ & 0.2602 & & \\
\hline$\geq 50$ & ref & & & \\
\hline Sex at Birth & & 0.0032 & & \\
\hline Male & $4.07(95 \%$ CI $1.60-10.38)$ & 0.0032 & $2.98(95 \%$ CI $0.82-10.77)$ & 0.0950 \\
\hline Female & ref & & ref & \\
\hline Race/Ethnicity & & 0.2637 & & \\
\hline Non-Hispanic White & $0.55(95 \%$ CI $0.30-1.02)$ & 0.0614 & & \\
\hline Non-Hispanic Black & ref & & & \\
\hline Hispanic & $0.77(95 \%$ CI $0.41-1.45)$ & 0.4252 & & \\
\hline Other & $1.14(95 \%$ CI $0.39-3.27)$ & 0.8034 & & \\
\hline Education Level & & 0.0383 & & \\
\hline High School or below & ref & & ref & \\
\hline Some college/tech/trade & $1.86(95 \%$ CI $1.02-3.39)$ & 0.0404 & $1.17(95 \%$ CI $0.59-2.29)$ & 0.6451 \\
\hline College/Graduate School & $1.99(95 \%$ CI $1.04-3.82)$ & 0.0373 & $1.21(95 \%$ CI $0.58-2.54)$ & 0.6032 \\
\hline Sexual Orientation & & $<0.0001$ & & \\
\hline Heterosexual & ref & & ref & \\
\hline $\begin{array}{l}\text { Gay or Lesbian, Bisexual, } \\
\text { Asexual, \& Other }\end{array}$ & $3.07(95 \%$ CI $1.72-5.47)$ & $<0.0001$ & $0.92(95 \%$ CI $0.34-2.64)$ & 0.8855 \\
\hline Gender of Sexual Partners & & 0.0138 & & \\
\hline Men only & ref & & ref & \\
\hline Women only & $0.34(95 \%$ CI $0.17-0.70)$ & 0.0034 & $0.60(95 \%$ CI $0.18-2.02)$ & 0.4164 \\
\hline Men \& Women & $0.82(95 \%$ CI $0.37-1.81)$ & 0.6360 & $0.71(95 \%$ CI $0.27-1.87)$ & 0.4910 \\
\hline Relationship Status & & 0.7961 & & \\
\hline Single/Divorced & ref & & & \\
\hline Married/Long-term partner & $0.91(95 \%$ CI $0.46-1.80)$ & 0.7961 & & \\
\hline $\begin{array}{l}\text { Number of Sexual Partners in the } \\
\text { prior } 12 \text { months }\end{array}$ & & $<0.0001$ & & 0.0128 \\
\hline $1-4$ & ref & & ref & \\
\hline$\geq 5$ & $2.88(95 \%$ CI $1.70-4.89)$ & $<0.0001$ & $2.20(95 \%$ CI $1.18-4.11)$ & 0.0128 \\
\hline Unprotected Sex in Prior 12 months & & 0.0357 & & 0.9566 \\
\hline No & ref & & ref & \\
\hline Yes & $1.81(95 \%$ CI $1.04-3.17)$ & 0.0357 & $1.01(95 \%$ CI $0.51-2.01)$ & 0.9566 \\
\hline \multicolumn{5}{|l|}{ Have you had a sexual partner... } \\
\hline $\begin{array}{l}\text {... who was HIV positive in the prior } \\
12 \text { months? }\end{array}$ & & 0.0073 & & 0.4558 \\
\hline No & ref & & ref & \\
\hline Yes & $2.05(95 \%$ CI $1.21-3.49)$ & 0.0073 & $1.28(95 \%$ CI $0.66-2.47)$ & 0.4558 \\
\hline
\end{tabular}




\begin{tabular}{|c|c|c|c|c|}
\hline $\begin{array}{l}\text {... who was HIV negative in the prior } \\
12 \text { months? }\end{array}$ & & 0.9048 & & \\
\hline No & ref & & & \\
\hline Yes & $0.96(95 \%$ CI $0.56-1.67)$ & 0.9048 & & \\
\hline $\begin{array}{l}\text {.. whom you did not know (anonymous } \\
\text { sex) or someone you just met? }\end{array}$ & & 0.0048 & & 0.6426 \\
\hline No & ref & & ref & \\
\hline Yes & 2.07 (95\% CI $1.24-3.44)$ & 0.0048 & $1.16(95 \%$ CI $0.61-2.17)$ & 0.6426 \\
\hline $\begin{array}{l}\text { Disclosed HIV Status to Casual Sex } \\
\text { Partners }\end{array}$ & & 0.8237 & & \\
\hline Not applicable & ref & & & \\
\hline Most or all/Some & $1.16(95 \%$ CI $0.59-2.27)$ & 0.6576 & & \\
\hline None or hardly any & $0.95(95 \%$ CI $0.38-2.38)$ & 0.9270 & & \\
\hline
\end{tabular}




\title{
Manuscript 3
}

(C) Copyright 2019

\section{Demographics, Risky Sexual Behaviors, and Venue Type selection as parameters for the prediction of Sexually Transmitted Disease among persons living with HIV: An Analysis Using Bayesian Networks}

\begin{abstract}
The purpose of this study was to examine factors influencing the incidence of sexually transmitted disease (STD) among Florida Cohort Study participants by examining participant demographics, risky sexual behaviors, and their choice of venue to meet new sexual partners utilizing Bayesian network (BN) analysis. Bayesian networks are a type of statistical modeling, which allows researchers to obtain a graphical network of variables and outcomes using empirical data. For this study, a total of three networks were developed including one literaturebased network and two learned Banjo and bnlearn Bayesian networks. Overall, the banjo model fit the cohort study data three times better than the bnlearn model. The banjo model suggests that technology usage influences number of sexual partners, reporting a history of STDs, having an HIV positive sexual partner, having unprotected sex, and having anonymous sex. The model also suggests a pathway between these variables. The study concludes that learned Bayesian networks can be utilized in the context of examining the relationships between technology, demographics, risky sexual behaviors, and STDs.

KEYWORDS: HIV, AIDS, Bayesian Networks, DAG, Conditional Probability, STDs, Venue type
\end{abstract}


Introduction

The incidence of sexually transmitted diseases (STDs) are on the rise, nationwide (World Health Organization, 2015). In Florida the incidence of bacterial STDs has increased from 425.3 per 100,000 persons per year in 2006 to 684.7 per 100,000 persons per year in 2017 (Florida Charts, 2018). This rise in STDs has gone hand-in-hand with the recent advancement of technology, beginning with at-home internet in the early 1990s to the introduction of social networking smartphone applications (SNSA) on mobile Smartphones in the late 2000s (Grov et al., 2011; Klausner et al., 2011; Winetrobe et al., 2014).

According to the Pew Research Center, the proportion of Americans who have used a dating site and/or mobile application increased from 11 to 15\% between 2013 and 2016 (Smith et al., 2016). Risks associated with the internet and SNSAs have been well established within menwho-have-sex-with-men (MSM) populations. Research has documented a higher number of sexual partners, unprotected sexual acts, consumption of alcohol in conjunction with sexual activity, more sexually transmitted infections among these Internet and SNSA users (McFarlane et al., 2000; Seal et al., 2015; Benotsch et al., 2011; Bull et al., 2000; Garofalo et al., 2007; Horvath et al., 2006; McFarlane et al., 2002; McKirnan et al., 2007; Davis et al., 2006; Landovitz et al., 2013; Lehmiller et al., 2014). A recent systematic review examining risk-taking behavior among heterosexuals found mixed associations between online partner-seeking and condom use or STDs (Tsai et al., 2018). However, the review did not take into account potential moderators, such as age or gender (Tsai et al., 2018).

Research also suggests that venue-specific characteristics, including alcohol in bars and anonymous chat rooms, can impact how MSM negotiate sexual risk behavior. Social norms within each venue have been suggested to play a role in how, for example, MSM negotiate HIV- 
associated risk behaviors, such as serostatus disclosure and condom use (Binson et al., 2010). However, limited research has been conducted among women and people living with HIV. One study found that $43 \%$ of adult women reported having sex with a person they first met on the Internet (McFarlane et al., 2004). These women were also found to have higher self-reported rates of STDs, inconsistent condom usage, and reported engaging in anal, oral, and vaginal sex with Internet partners (McFarlane et al., 2004). Demographics including age group and race/ethnicity have also been found to be associated with technology use to meet sexual partners within MSM populations, but these variables have yet to be examined with regards to modernday technology in the form of social networking smartphone applications (SNSAs) (Beymer et al., 2014; Burrell et al., 2012). Overall, very little research has focused on the interaction between technology use, demographics, risky sexual behaviors, and sexually transmitted disease within a non-MSM population.

Bayesian networks (BNs) are a type of statistical modeling, which allows researchers to obtain a graphical network of variables and outcomes using empirical data (Cooper et al., 1999; Pearl et al., 1988; Su et al., 2013; Neapolitan et al., 2003; Kim et al., 2014). Bayesian networks consist of two components: 1) a network structure in the form of a directed acyclic graph (DAG) and 2) a set of conditional probability distributions, one for each variable, characterizing the stochastic dependencies between edges. In a DAG, variables are represented by nodes that can hold multiple states. Arcs denote relationships between the nodes. If there is a directed edge between node $\mathrm{Y}$ to node $\mathrm{Z}$, for example, then $\mathrm{Y}$ is the parent of $\mathrm{Z}$; likewise $\mathrm{Z}$ is called the child of Y. Probabilities assigned to each node are based on the probability of the parent nodes. In a $\mathrm{BN}$, each variable represented by a node is believed to be conditionally independent of all its predecessors in the graph, given the values of its parents. According to Pearl et al., the absence 
of an arc between any two nodes implies that the variables are independent given the values of any intermediate nodes (Pearl et al., 1988; Kim et al., 2014; Pearl et al., 2000). This is known as the Markov condition, which states that the joint probability distribution for the entire set of variables represented by a $\mathrm{BN}$ can be decomposed into a product of conditional probabilities using the graphical structure and the chain rule of probability:

$$
\left.p(\boldsymbol{x} \mid \boldsymbol{\theta}))=\prod_{i=1}^{n} p\left(x_{i} \mid p a\left(x_{i}\right), \theta_{i}\right)\right)
$$

where $x=\{x 1, \ldots x n\}$ are the variables (nodes in the $\mathrm{BN}$ ) and $\boldsymbol{\theta}=\{\theta 1, \ldots, \theta n\}$ are the BN's parameters, where each $\theta i$ is the set of parameters necessary to specify the distribution of the variable $x i$ given its parents pa(xi) (Su et al., 2014; Neapolitan et al., 2003; Pearl et al., 2000). For example, if age and gender were parent nodes to using technology_if you knew a participants age and gender then you could predict the probability of the participant using technology to meet new sex partners.

In BNs there are three possible pathways for interactions between nodes: converging, diverging, and serial. For example, in Figure 1, age and gender are converging structure as the parent nodes to technology, which implies that if you know the age of a participant and whether they use technology then you can predict their gender. For diverging and serial structures, which are considered equivalent, in Figure 1, technology is the parent node to both anonymous sex and the number of sex partners, then if you know the number of sex partners and technology usage then you cannot predict whether they engage in anonymous sex.

Relationships between variables not directly connected to each other can be deduced from the conditional dependencies and independencies shown in the arcs and nodes in between 
those variables in the DAG structure. These models can visualize interaction of causes and rule out indirect causes of events (Su et al., 2013). They are used to identify parameters to predict an outcome. Similar models have been used in clinical settings to predict health outcomes (Kim et al., 2014). To date, these models have never been used in the context of predicting sexually transmitted diseases (STDs) using data pertaining to risky sexual behaviors and type of location where an individual meets sexual partners; however, these models could be used to guide prevention measures concerning STDs, social networking smartphone applications (SNSAs), and the Internet.

\section{Purpose of the Study}

The purpose of this study was to examine factors influencing the incidence of sexually transmitted disease among people living with HIV by examining participant demographics, risky sexual behaviors, and their choice of venue to meet new sexual partners using BNs. Figure 1 illustrates the hypothesized nodes and arc pathways of a literature-based BN (Figure 1). Demographics including age group and race/ethnicity have been found to be associated with technology (Beymer et al., 2014; Burrell et al., 2012). Most of the research examining risks associated with technology have focused on populations of MSM; two studies have found that women reported utilizing the internet and technology to meet sexual partners (Benotsch et al., 2011; McFarlane et al., 2002). One study found a significant difference in technology usage by gender (Seal et al., 2015). This same study also found significant differences in technology usage by sexual orientation, as such, sexual orientation was included as a node (Seal et al., 2015). App users have been to be more likely to report a higher number of sexual partners A study found that MSM app users were more likely to report unprotected sex and unprotected anal sex, as 
such, unprotected sex was included in the pathways as a parent node to sexually transmitted disease (Bien et al., 2015; Winetrobe et al., 2014). In a study among MSM, HIV status was not found to be associated with app usage; however, we wanted to see if having an HIV positive sexual partner was associated with technology within our population of PLWHAs (Rendina et al., 2014). Previous logistic regression of this Florida Cohort Study dataset found that individuals meeting new sexual partners using "Technology" methods are more likely to report unprotected sex in the prior 12 months and a history of syphilis than individuals utilizing only "NonTechnology" methods (Griffin et al., under review). Multivariate logistic regression found that participants who reported "technology-only" methods were younger compared to individuals who reported using both "technology \& in-person" methods (Griffin et al., under review). Similar analyses found that individuals who reported "in-person" only venues were less likely to report being gay/lesbian, over the age of 50, and were less likely to report being Non-Hispanic White compared to participants who reported using both "technology \& in-person" methods (Griffin et al., under review).

For this study, in addition to examining the hypothesized literature-based model, learned BNs will examine the relationship known STD risk factors (demographics, condom-usage, number of sexual partners) and variable of interest venue type. This will be accomplished utilizing BnLearn and Banjo software which is designed to learn $\mathrm{BN}$ structures from a dataset of variables. The main purpose of constructing these models is to be able to predict STD history of a new study participant in the Florida Cohort Study, and hopefully utilize these structures to help fill gaps in knowledge concerning the use of technology and STDs. 
Methods

Study Population

Between October 2014 and September 2017, 932 persons living with HIV/AIDS (PLWHA) were recruited into the Florida Cohort Study. The Florida Cohort Study recruited from a collaborative network of county health department and community clinics, and settings throughout Florida, including sites at Lake City, Gainesville, Tampa, Orlando, Sanford, Ft. Lauderdale, and Miami. Inclusion criteria for the study include being over the age of 18, HIV positive, and living in the state of Florida. After written informed consent was obtained, participants completed a Research Electronic Data Capture (REDCap®) survey in English or Spanish. Surveys took approximately 30-45 minutes to complete, and participants were provided a \$25 gift card upon completion (Ibanez et al., under review; Lucero et al., 2017; Sharpe et al., 2018). The cross-sectional survey asked participants questions about their demographics, how they met new sexual partners in the past 12 months (defined in this study as venue), and their sexual history. The Florida Cohort Study was approved by Institutional Review Boards (IRBs) at the University of Florida, Florida International University, and the Florida Department of Health; and this research study was approved by Florida International University’s IRB.

Among the 932 Florida Cohort Study respondents, 705 were excluded from analysis. Individuals who reported not having sex in the prior 12 months $(n=275)$, meeting a new sexual partner in the prior 12 months $(n=333)$, or a venue where they had met a new sexual partner $(n=52)$ were excluded from the analysis, or did not respond to question for a specific variable of interest $(n=45)$. 
Demographic variables of interest included age-group (18-29, 30-39, 40-49, $\geq 50)$, sex at birth (male or female), race/ethnicity (Non-Hispanic White, Non-Hispanic Black, Hispanic, Other), and self-reported sexual orientation (heterosexual, gay or lesbian, bisexual).

Venue-type was determined based on how participants responded to locations where they had met new sexual partners in the prior 12 months (internet, SNSAs, bar, club, bathhouse, massage parlor, work, and/or friend, and other). Given small samples sizes for some locations, individual venues were grouped into venue-types: "Technology" (any Internet and/or SNSAs) or "Non-Technology" (only bar or club, bathhouse, massage parlor, work, and/or friend, and/or other). The Florida Cohort Study did not ask for additional information concerning "other"; however, due to the exhaustive list of "technology" options it is believed that the "other" venue is a "Non-Technology" venue. The Florida Cohort Study did not ask for additional information concerning "Other", so at this current time it is unknown what other venues fall into the category of “Other". Individuals who did not report meeting a new sex partner in the prior 12 months, did not provide a venue-type, and/or had missing variables (unknowns) were excluded from analysis.

Risky sexual behaviors included a self-reported categorical range of sexual partners in the previous 12 months (None, $\leq 10,>10$ ) and the number of unprotected sexual partners in the previous 12 months (None, $\leq 10,>10$ ). Participants were also asked whether they had an anonymous sex partner or a partner with HIV/AIDS in the prior 12 months. Due to small sample size, this response was made binary (i.e. "yes" or "no"). 
Sexually transmitted disease included self-reported lifetime history of chlamydia, syphilis, genital herpes, and genital warts. Lifetime STD history was reclassified as a binary variable (i.e. "never" vs "ever") due to small sample size.

\section{Data analysis}

Descriptive statistics were conducted in SAS 9.4. A hypothesized BN structure was created based on associations between the variables of interest noted in the literature (Figure 1). For example, one study found a significant difference in technology usage by gender (Seal et al., 2015). This same study also found significant differences in technology usage by sexual orientation, as such, sexual orientation and gender were included as a parent node to technology in the literature based model (Figure 1) (Seal et al., 2015). Literature based Bayesian network model was generated using GENIE software. The BN learning software Banjo (Figure 2) and bnlearn R package (Figure 3) were utilized to examine relationships between demographics, risky sexual behaviors, and sexually transmitted diseases using data from the Florida Cohort Study (Hartemink et al., 2005; Scutari et al., 2010). In banjo, learning was accomplished using static Bayesian network inference involving three 60-minute runs to identify the best three networks ( $\mathrm{n}=227)$ (Figure 2). This proposed network was imported into bnlearn to calculate a Bayesian Dirichlet equivalent (bde) score. In bnlearn, learning was accomplished using a hill climbing $(\mathrm{HC})$ bde score-based structure algorithm $(\mathrm{n}=227)$ (Figure 3$)$. The bde scores were normalized using a log normalization function in Rstudio to allow for bde score comparisons between structures. Goodness of fit analysis (ROC) was performed in SAS 9.4 for syphilis, chlamydia, genital herpes, and genital warts with the variables of interest.

To further compare the literature based Bayesian network model with the Florida Cohort Study data based Bayesian network model, conditional probabilities for variables with a single 
parent node were calculated to determine whether these conditional probabilities were consistent with the learned Banjo model (the best model) or the literature based model. The top three conditional dependence (lowest three p-values) and the top three conditional (highest p-values) independencies which disagreed with either the banjo or literature-based model were identified (Appendix). In addition, The top three conditional dependence (lowest three p-values) and the top three conditional (highest p-values) independencies for technology were also compared to the banjo and literature-based models (Table 1; Table 2).

Results

Among the 932 Florida Cohort Study respondents, 705 were excluded from analysis. Individuals who reported not having sex in the prior 12 months $(\mathrm{n}=275)$, meeting a new sexual partner in the prior 12 months ( $\mathrm{n}=333)$, or a venue where they had met a new sexual partner $(n=52)$ were excluded from the analysis, or did not respond to question for a specific variable of interest $(\mathrm{n}=45)$. Among the 227 participants included in the analyses, $110(48.5 \%)$ reported “Technology” venues and 117 (51.5\%) "Non-Technology” venues. Most participants were male $(n=202,88.9 \%)$, over the age of forty $(n=136,59.9 \%)$ with median age of 44 years (range $19-$ 68), and Non-Hispanic Black/African American ( $\mathrm{n}=99,43.6 \%)$.

\section{Maximum likelihood model}

According to the learned maximum likelihood model (banjo) network, gender and sexual orientation were strong predictors (parent nodes) of technology usage (Figure 2). Technology use was a strong predictor (parent node) of age and race/ethnicity of a participant. Technology was 
also a parent node of the number of sexual partners which was the parent node to all STDs.

Finally, Technology was the parent node of reporting an HIV positive partner. Reporting an HIV positive partner was predictive of engaging in unprotected sex. Both unprotected sex and number of sexual partners were predictive of reporting anonymous sex partners. The bde score for this network (calculated in bnlearn to allow for comparison between learned DAGs) was -1932.19. Normalization of bde score was equal to 0.7320405 .

Other model with significant (>1\%) likelihood

In the other model with significant (>1\%) likelihood (bnlearn), gender and sexual orientation were parent nodes to technology (Figure 3). Technology was a parent node to age, race/ethnicity, and having an HIV positive sexual partner in the prior 12 months. Gender, orientation, anonymous sex, and number of sexual partners were strong predictors of all STDs, resulting in a similar pathway to the Banjo model. Gender, orientation, anonymous sex, and number of sexual partners were predictors of unprotected sex. Gender, orientation, anonymous sex, and number of sexual partners were also predictors of sex with HIV positive partners. The bde score for this network was -1933.195 . Normalization of the bde score was equal to 0.2679595 .

\section{Conditional probabilities}

Overall, the calculated independent conditional probabilities were consistent with the Banjo model but appeared to disagree with the conditional probabilities suggested in the literature-based model (Appendix: Table 1). Regarding the dependencies, both banjo and the 
conditional probabilities suggest that genital warts and genital herpes are dependent on one another; however, this is not consistent with the literature (Appendix: Table 2). Furthermore, the top independencies and dependencies for technology agree with the literature-based model and banjo that technology is associated with sexual orientation (Appendix Table 1; Appendix Table 2). This finding is consistent with previous studies which utilized univariate analysis on this dataset (Griffin et al., under review; Griffin et al., under review). However, both the literature and banjo disagree with the conditional probability of independence between technology and genital herpes and genital warts (Table 1).

\section{Goodness of Fit Analysis}

Goodness of fit (ROC) analysis found that the variables included in the models were able to predict the outcome of syphilis $74.77 \%$ of the time, $67.21 \%$ for chlamydia, $76.71 \%$ for genital herpes, and $70.64 \%$ for genital warts. Overall, both the Bayesian network analysis and goodness of fit analysis suggest that the included variables in the model are sufficient at predicting the STD outcomes of interest.

Discussion

Based on a comparison of the log normalized bde scores for the bnlearn and banjo model, the maximum likelihood model (banjo) fit the data three times better than the model with significant (>1\%) likelihood (bnlearn). According to the learned banjo network, gender and sexual orientation were strong predictors of technology usage (Figure 2). Technology appeared to serve as a parent node to several variables, including demographic (age and race/ethnicity), 
risky sexual behaviors (number of sexual partners and HIV positive partner), and reporting a history of STDs.

\section{Technology \& Demographics}

The literature and banjo both agree with the probabilities that technology is associated with sexual orientation (Seal et al., 2015). The networks suggest that sexual orientation and gender directly predict technology usage. This is consistent with the literature which found statistically significant differences in technology-usage among different sexual orientations and to previous logistic regression analyses of Florida Cohort Study participants which found similar findings (Seal et al., 2015; Griffin et al., under review; Griffin et al., under review).

\section{Technology \& Risky Sexual Behaviors}

Based on both learned networks (Figures 2-3), technology was a strong predictor of having an HIV positive sexual partner. In a previously mentioned study among MSM, HIV status was not found to be associated with app usage; however, technology is associated with having an HIV positive sexual partner within our population of PLWHAs (Rendina et al., 2014). This connection may suggest that PLWHAs may utilize technology methods to engage in serosorting. Engagement in serosorting behaviors may also bias STD reporting history as serosorting has been historically associated with incidence of STDs (Suarez et al., 2001; Rietmeijer et al, 2007; Eaton et al., 2011). Researchers should examine the role of technology and engaging in this partner section behavior in future studies.

Overall, technology usage appears to be associated with engaging in risky sexual behaviors within the learned model. This is consistent with the literature which has documented 
a higher number of sexual partners and unprotected sexual acts among these Internet and SNSA users (McFarlane et al., 2000; Seal et al., 2015; Benostch et al., 2011; Bull et al., 2000; Garofalo et al., 2007; Horvath et al., 2006; McFarlane et al., 2002; McKirnan et al., 2007; Davis et al., 2006; Landovitz et al., 2013; Lehmiller et al., 2014).

\section{Technology \& STDs}

As previously mentioned, conditional probabilities were fairly consistent with the literature-based and banjo models; however, conditional probability analysis suggested that genital herpes and genital warts are dependent variables. We hypothesize that this association may be due to the self-report nature of STDs in the survey and that maybe study participants may not be able to differentiate between an STD history of genital herpes or genital warts. The same analysis also suggests that technology and reporting a history of genital warts or genital herpes is independent. Again, this analysis conflicts the literature which has documented a higher number of sexual partners among technology users and the banjo model which suggests that these two nodes are dependent (Lehmiller et al., 2014; Rendina et al., 2014). However, overall it appears that technology usage does influence reporting a history of STDs and the banjo model appears to predict this likelihood.

\section{Conditional Probabilities}

Furthermore, overall conditional probabilities appeared to disagree with conclusions found in the literature. Specifically, the analysis suggested that a participant's age is independent

of the number of sexual partners, that a participant engaging in unprotected sex is independent of 
engaging in anonymous sex, and that a participant's gender is independent of reporting a history of genital warts. This finding conflicts with literature which found associations between age and number of sexual partners, and literature which notes the associations between unprotected sex and sex genital herpes, and the Centers for Diseases Control and Prevention notes differences in gender and STDs (women are less like to be diagnosed than men) (Haderxhanaj et al., 2018; CDC, 2019; CDC 2019). The R code created by Florida International University's Department of Biostatistics used to calculate the aforementioned conditional probabilities is currently in development. As such, the results for conditional probability should be interpreted with caution and future studies should examine the sensitivity and specificity of the code in calculating independent and dependent conditional probabilities.

\section{Conclusions}

This study represents the first time learned Bayesian networks have been used in the context of data pertaining to the type of location where an individual meets sexual partners, risky sexual behaviors, and sexually transmitted diseases. Overall, the maximum likelihood model (banjo) was three times better than the model with significant $(>1 \%)$ likelihood (bnlearn). The banjo model suggests that technology usage directly influences number of sexual partners, reporting a history of STDs, having an HIV positive sexual partner, having unprotected sex, and having anonymous sex. The model also suggests a pathway between these variables. The study concludes that learned Bayesian networks can be utilized in the context of examining the relationships between technology, demographics, risky sexual behaviors, and STDs. 


\section{References}

Benotsch, E, Martin A, Espil F, et al. "Internet use, recreational travel, and HIV risk behaviors in men who have sex with men." 2011. Journal of Community Health. (36):398-405.

Beymer M, Weiss R, Bolan R, et al. "Sex on demand: geosocial networking phone apps and risk of sexually transmitted infections among a cross-sectional sample of men who have sex with men in Los Angeles county.” 2014. Sex Transm Infect. 90:567-572.

Bien C, Best J, Muessig K. "Gay Apps for Seeking Sex Partners in China: Implications for MSM Sexual Health.” 2015. AIDS Behav. 19:941-946.

Binson D, Pollack LM, Blair J, et al. "HIV transmission risk at a gay bathhouse. J Sex Res." 2010. 47(6):580-588.

Bull, S., \& McFarlane, M. "Soliciting sex on the Internet - what are the risks for sexually transmitted diseases and HIV." 2000. Sexually Transmitted Diseases. 27(9): 545-550.

Burrell E, Pines H, Robbie E, et al. "Use of the location-based social networking application GRINDR as a recruitment tool in rectal microbe development research." 2012. AIDS Behav. 16:1816-1820.

Centers for Disease Control \& Prevention [CDC]. "Genital Herpes - CDC Fact Sheet." Retrieved from https://www.cdc.gov/std/herpes/stdfact-herpes.htm on August 5, 2019.

Centers for Disease Control \& Prevention [CDC]. "10 ways STDs impact women differently from men." Retrieved from https://www.cdc.gov/std/health-disparities/stds-women-042011.pdf on August 5, 2019.

Cooper et al. "Causal Discovery from a Mixture of Experimental and Observational Data. Proceedings of Uncertainty in Artificial Intelligence.” 1999. p116-125.

Davis M. "Sex and the Internet: Gay men, risk reduction and serostatus." Cult Health Sex. 2006. 8:161-174.

Druzdzel, M. "SMILE: Structural Modeling, Inference, and Learning Engine and GeNIe: A Development Environment for Graphical Decision-Theoretic Models. In Proceedings of the Sixteenth National Conference on Artificial Intelligence (AAAI-99)". 1999. 902-903.

Eaton L, Kalichman S, Cain D, et al. "Serosorting Sexual Partners and Continued Risk for HIV Transmission among Men who have Sex with Men.” 2011. Am J Prev Med. 33(6):479-485.

Florida Charts (2018). Total Bacterial STDs. Florida Department of Health, Bureau of Communicable Diseases. Retrieved from:

http://www.flhealthcharts.com/charts/OtherIndicators/NonVitalSTDDataViewer.aspx?cid=9767

Garofalo R, Herrick A, Mustanski B, et al. "Tip of the iceberg: Young men who have sex with men, the Internet, and HIV risk.” 2007. Amer J Public Health. (97):1113-1117.

Griffin I, Fennie K, Yoo C, et al. "Examining Venue Selection, Risky Sexual Behaviors, and Sexually Transmitted Diseases among persons living with HIV, Florida. 2014-2017." Under review. 
Griffin I, Fennie K, Yoo C, et al. "Methods of meeting new sexual partners by demographic and HIV status disclosure among persons living with HIV by physical and virtual venue type, Florida, 2014-2017." Under review.

Grov C, et al. "Exploring the Venue: Role in Risky Sexual Behavior Among Gay and Bisexual Men: An Event-Level Analysis from a National Online Survey in the U.S." 2011. Archives of Sexual Behavior. 42 (2): 291-302.

Haderxhanaj L, Leichliter J, Aral S, Chesson H. "Sex in a Lifetime: Sexual Behaviors in the United States by Lifetime Number of Sex Partners, 2006-2010." Sex Transm Dis. 2018. 41(6): 345-352.

Hartemink. Banjo (bayesian network inference with java objects). 2005. URL http://www.cs. duke.edu/ amink/software/banjo.

Horvath K, Bowen A, Williams M. "Virtual and physical venues as contexts for HIV risk among rural men who have sex with men." 2006. Health Psychology. (25): 237-242.

Ibanez G, Zhou Z, Cook C, et al. "The Florida Cohort Study: Methodological challenges and lessons learned in the design and implementation of a new cohort of persons living with HIV (PLWH)." Under Review.

Kim M, Cheeti A, Yoo C, et al. Non-Invasive Clinical Parameters for the Prediction of Urodynamic Bladder Outlet Obstruction: Analysis Using Causal Bayesian Networks. 2014. PLOS ONE: 9 (11).

Klausner J. "Chapter 13: Tracking a Syphilis Outbreak Through Cyberspace. Cases in Field Epidemiology: A Global Perspective. Sudbury, MA: Jones \& Bartlett Learning." 2013. (13): 163-71.

Landovitz R, Tesent C, Weissman M, et al. "Epidemiology, Sexual Risk Behavior, and HIV Prevention Practices of Men who have Sex with Men Using GRINDR in Los Angeles, California." 2013. J Urban Health. 90(4): 729-739.

Lehmiller J, Loerger M, et al. "Social networking Smartphone applications and sexual health outcomes among men who have sex with men." 2014. PloS One. 9(1): e86603.

Lucero R, Frimpong J, Fehlberg E, et al. "The Relationship Between Individual Characteristics and Interest in Using a Mobile Phone App for HIV Self-Management: Observational Cohort Study of People Living with HIV.” 2017. JMIR. 5(7):100.

McFarlane M, Bull S, Rietmeijer C., et al. "The Internet as a newly emerging risk environment for sexually transmitted diseases.” 2000. JAMA. 284(4): 443-446.

McFarlane M, Bull S, Rietmeijer C., et al. "Young adults on the Internet: Risk behaviors for sexually transmitted diseases and HIV." JAMA. 2002. (31): 11-16

McFarlane M, Kachur R, et al. "Women, the Internet, and Sexually Transmitted Infections." 2004. J Women's Health. 13 (6): 689-694.

McKirnan D, Houston E, Tolou-Shams M. "Is the Web the culprit? Cognitive escape and Internet sexual risk among gay and bisexual men.” 2007. AIDS Behav. (11): 151-160. 
Neapolitan R. "Learning Bayesian networks.” 2003. Upper Saddle River: Pearson Prentice Hall. Pearl J. "Probabilistic Reasoning in Intelligent Systems." 1988. Morgan Kaugmann, San Mateo, CA.

Pearl J. “Causality: models, reasoning, and inference.” 2000. Cambridge: Cambridge University Press.

Rendina H, Jimenez R, Grov C, et al. "Patterns of Lifetime and Recent HIV Testing Among Men Who Have Sex with Men in New York City Who Use Grindr.” 2014. AIDS Behav. 18:41-49.

Rietmeijer C, Lloyd L, McLean C. "Discussing HIV serostatus with prospective sex partners: A potentional HIV prevention strategy among high-risk men who have sex with men.” 2007. Sexually Transmitted Diseases. 34:215-219.

Scutari. "Learning Bayesian Networks with the bnlearn R package." 2010. Journal of Statistical Software. 35(3): 1-22.

Seal D, Benotsch E, Green M, et al. "The use of internet chat rooms to meet sexual partners: A comparison of non-heterosexually identified men with heterosexually identified men and women.” 2015. Int J Sex Health. 27(1):1-15.

SHARC Questionnaire. "Southern HIV and Alcohol Research Consortium (SHARC)." University of Florida. Retrieved from: http://sharc-research.org/wpcontent/uploads/2017/07/Phase1_Orange_bs_v2_120314.pdf

Sharpe J, Zhou Z, Cesar G, et al. "Interest in using mobile technology to help self-manage alcohol use among persons living with the human immunodeficiency virus: A Florida Cohort cross-sectional study.” 2018. Substance Abuse. 39 (1): 77-82.

Smith A. " $15 \%$ of American adults have used online dating sites or mobile dating apps." Retrieved from: https://www.pewinternet.org/2016/02/11/15-percent-of-american-adults-haveused-online-dating-sites-or-mobile-dating-apps/

Su C, Andrew A, Karagas M, et al. "Using Bayesian networks to discover relations between genes, environment, and disease.” 2103. BioData Min. 6:6.

Suarez T, Kelly J, Pinkerton S, et al. “Influence of a partner's HIV serostatus, use of highly active antiretroviral therapy, and viral load on perceptions of sexual risk behavior in a community sample of men who have sex with men.” 2001. JAIDS. 28:471-7.

Tsai J, Sussman S, Pickering T. "Is Online Partner-Seeking Associated with Increased Risk of Condomless Sex and Sexually Transmitted Infections Among Individuals Who Engage in Heterosexual Sex? A Systematic Narrative Review.” 2018. Arch Sex Behav.

Winetrobe H. "Associations of Unprotected Anal Intercourse with Grindr-met Partners among Grindr-using Young Men Who Have Sex with Men in Los Angeles.” 2014. AIDS Care. 26 (10): 1303-308.

World Health Organization. "Global Estimates Shed Light on Toll of Sexually Transmitted Infections." 2015. Retrieved from: http://www.who.int/reproductivehealth/news/stis-estimates2015/en/ 
Figure 1. GENIE network: A Bayesian Network (BN) structure drawn from the literature utilizing GENIE ( $n=227)$.

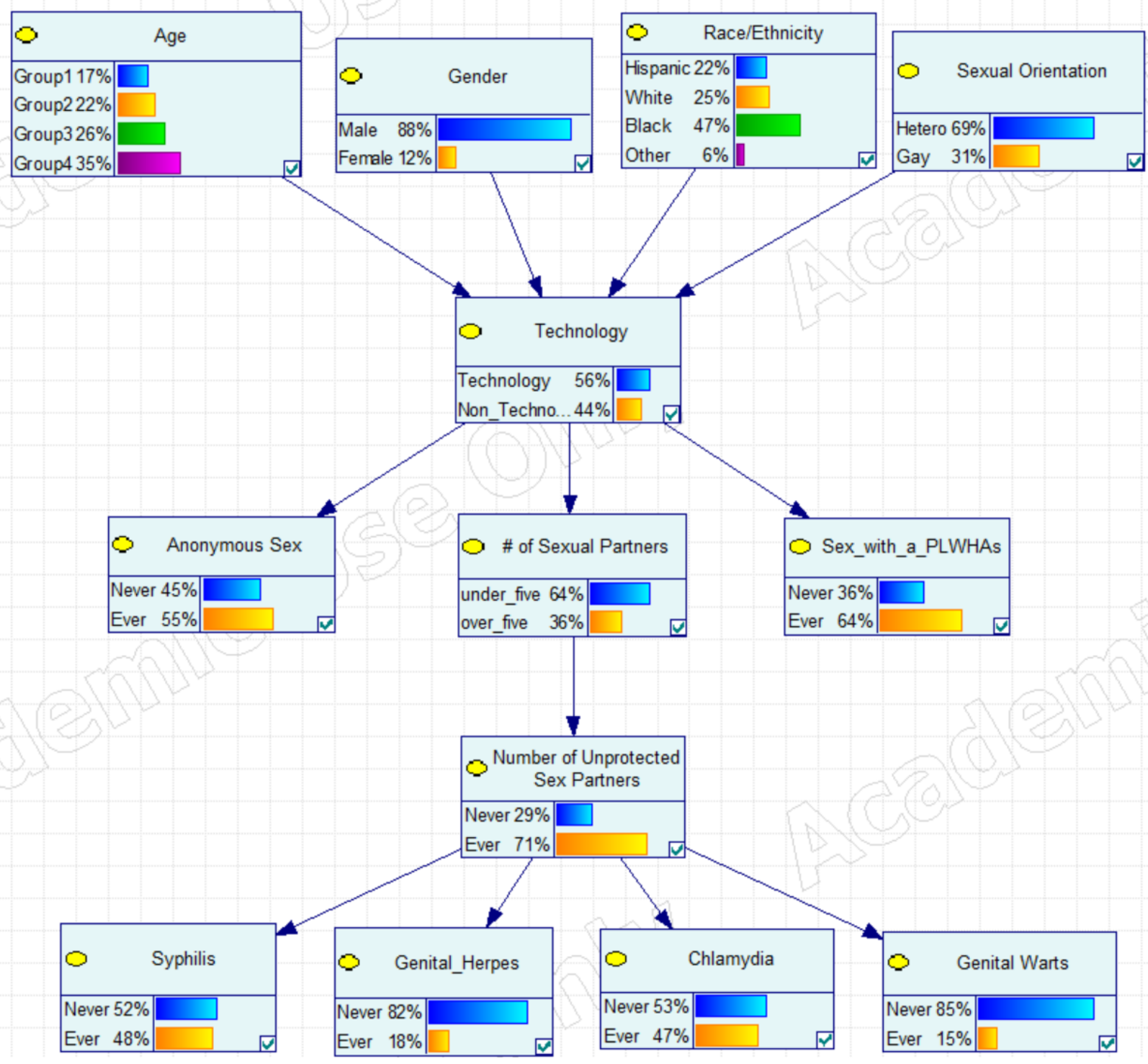


Figure 2. Banjo Network: A Bayesian Network (BN) structure (Maximum Likelihood Model) learned from the Florida Cohort Study sample scored in R bnlearn $(n=227)$. [BDE score $=-$ 1932.19, Log Normalization $=0.7320405$ ]

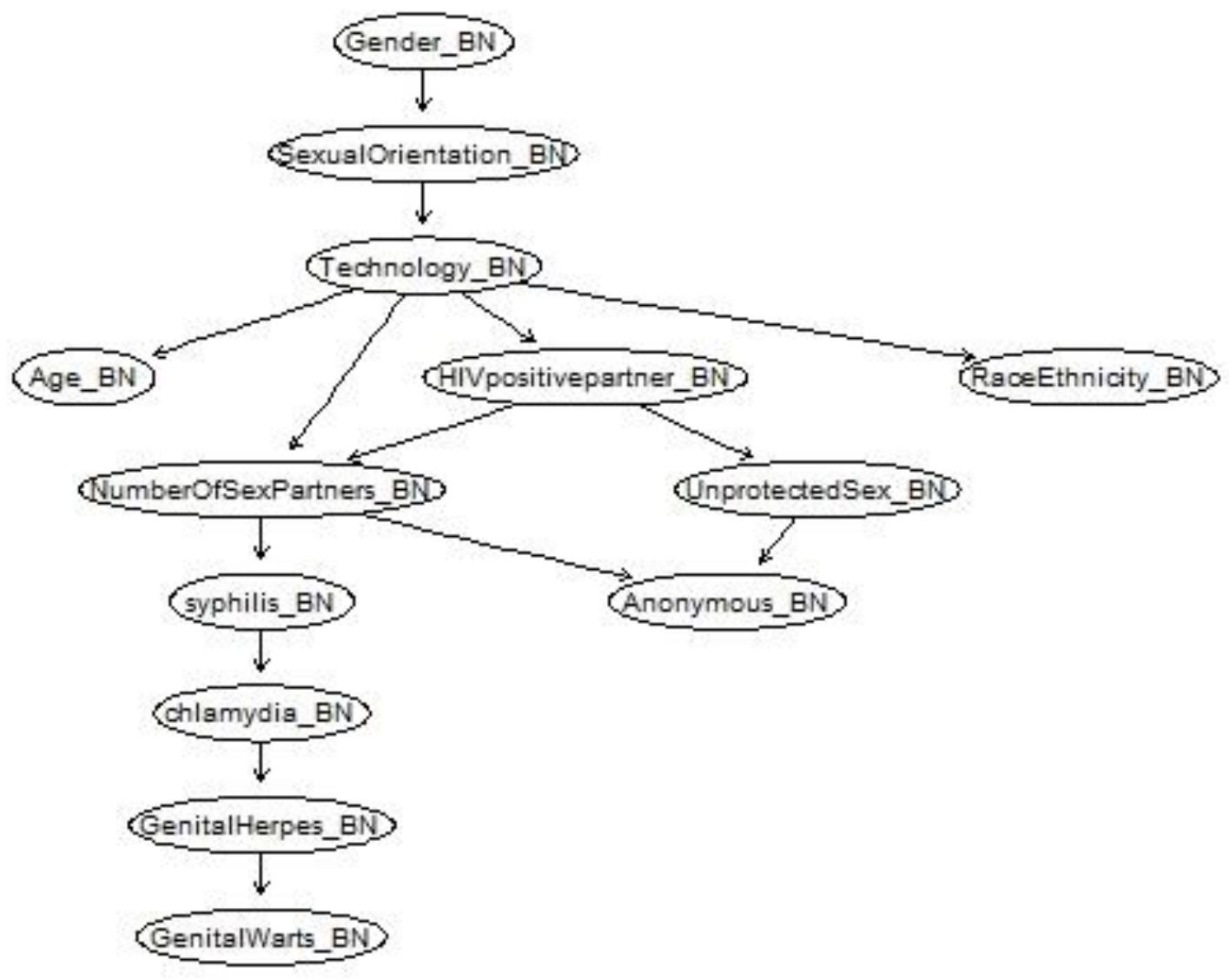


Figure 3. Bnlearn Network: A Bayesian Network (BN) structure (significant [ $>1 \%]$ likelihood model) learned from the Florida Cohort Study sample in $\mathrm{R}$ bnlearn package and scored in $\mathrm{R}$ bnlearn $(\mathrm{n}=227)$. [BDE score $=-1933.195$, Log Normalization $=0.2679595]$

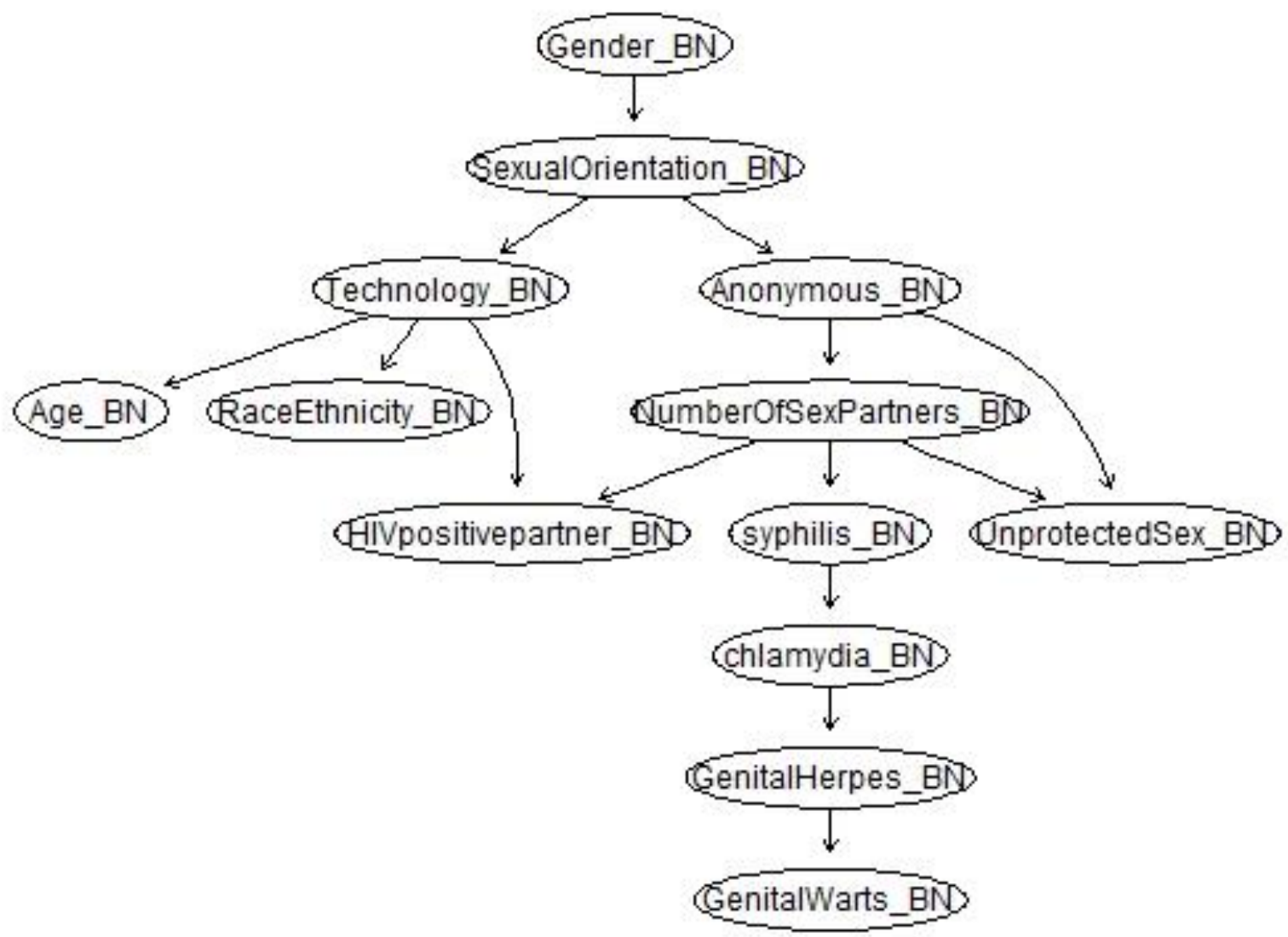


Table 1. Top Independent Conditional Probabilities ( $\mathrm{p}$-value > 0.05) Contradicting Banjo and/or Literature-based Models $(n=227)$

\begin{tabular}{|c|c|c|c|c|c|c|}
\hline \multicolumn{4}{|c|}{ Conditional Probability Analysis } & \multirow[b]{2}{*}{$\begin{array}{l}\text { Conditional } \\
\text { Probability }\end{array}$} & \multirow[b]{2}{*}{$\begin{array}{c}\text { Literature- } \\
\text { based } \\
\text { Model }\end{array}$} & \multirow[b]{2}{*}{$\begin{array}{l}\text { Banjo } \\
\text { Model }\end{array}$} \\
\hline Node \#1 & Node \#2 & Given Node & p-value & & & \\
\hline Age & $\begin{array}{l}\text { \# Sex } \\
\text { Partners }\end{array}$ & Unprotected & 0.999906513 & Independent & Disagree & Agrees \\
\hline $\begin{array}{l}\text { Unprotected } \\
\text { Sex }\end{array}$ & $\begin{array}{l}\text { Genital } \\
\text { Herpes }\end{array}$ & Anonymous & 0.99599683 & Independent & Disagree & Agrees \\
\hline Gender & $\begin{array}{l}\text { Genital } \\
\text { Warts }\end{array}$ & Age & 0.993123637 & Independent & Disagree & Disagree \\
\hline Technology & $\begin{array}{l}\text { Genital } \\
\text { Warts }\end{array}$ & $\begin{array}{l}\text { HIV + } \\
\text { Partner }\end{array}$ & 0.991313778 & Independent & Disagree & Disagree \\
\hline Technology & $\begin{array}{l}\text { Genital } \\
\text { Warts }\end{array}$ & Unprotected & 0.984047011 & Independent & Disagree & Disagree \\
\hline Technology & $\begin{array}{l}\text { Genital } \\
\text { Herpes }\end{array}$ & $\begin{array}{l}\text { \# Sexual } \\
\text { Partners }\end{array}$ & 0.947777272 & Independent & Disagree & Disagree \\
\hline Technology & $\begin{array}{l}\text { Genital } \\
\text { Warts }\end{array}$ & $\begin{array}{l}\text { \# Sexual } \\
\text { Partners }\end{array}$ & 0.929351305 & Independent & Disagree & Disagree \\
\hline Technology & $\begin{array}{l}\text { Genital } \\
\text { Warts }\end{array}$ & $\begin{array}{l}\text { Genital } \\
\text { Herpes }\end{array}$ & 0.901961701 & Independent & Disagree & Disagree \\
\hline Technology & $\begin{array}{l}\text { Genital } \\
\text { Warts }\end{array}$ & Anonymous & 0.894883732 & Independent & Disagree & Disagree \\
\hline Technology & $\begin{array}{l}\text { Genital } \\
\text { Warts }\end{array}$ & Syphilis & 0.862125276 & Independent & Disagree & Disagree \\
\hline Technology & $\begin{array}{l}\text { Genital } \\
\text { Warts }\end{array}$ & Chlamydia & 0.848710912 & Independent & Disagree & Disagree \\
\hline Technology & $\begin{array}{l}\text { Genital } \\
\text { Herpes }\end{array}$ & Unprotected & 0.766275282 & Independent & Disagree & Disagree \\
\hline Technology & $\begin{array}{l}\text { Genital } \\
\text { Herpes }\end{array}$ & Syphilis & 0.719556986 & Independent & Disagree & Disagree \\
\hline
\end{tabular}




\begin{tabular}{|l|l|l|l|l|l|l|} 
Technology & $\begin{array}{l}\text { Genital } \\
\text { Warts }\end{array}$ & Age & 0.696174833 & Independent & Disagree & Disagree \\
\hline Technology & $\begin{array}{l}\text { Genital } \\
\text { Herpes }\end{array}$ & Anonymous & 0.694196429 & Independent & Disagree & Disagree \\
\hline Technology & $\begin{array}{l}\text { Genital } \\
\text { Herpes }\end{array}$ & Chlamydia & 0.689721611 & Independent & Disagree & Disagree \\
\hline Technology & $\begin{array}{l}\text { Genital } \\
\text { Herpes }\end{array}$ & $\begin{array}{l}\text { Genital } \\
\text { Warts }\end{array}$ & 0.688053442 & Independent & Disagree & Disagree \\
\hline Technology & $\begin{array}{l}\text { Genital } \\
\text { Herpes }\end{array}$ & $\begin{array}{l}\text { HIV }+ \\
\text { Partner }\end{array}$ & 0.675366497 & Independent & Disagree & Disagree \\
\hline Technology & $\begin{array}{l}\text { Genital } \\
\text { Warts }\end{array}$ & Gender & 0.673179803 & Independent & Disagree & Disagree \\
\hline
\end{tabular}


Table 2. Top Dependent Conditional Probabilities ( $\mathrm{p}$-value $\leq 0.05$ ) contradicting Banjo and/or Literature-based Models $(\mathrm{n}=227)$

\begin{tabular}{|c|c|c|c|c|c|c|}
\hline \multicolumn{4}{|c|}{ Conditional Probability Analysis } & \multicolumn{3}{|c|}{-} \\
\hline Node \#1 & Node \#2 & Given Node & p-value & $\begin{array}{l}\text { Conditional } \\
\text { Probability }\end{array}$ & $\begin{array}{l}\text { Literature- } \\
\text { based Model }\end{array}$ & $\begin{array}{l}\text { Banjo } \\
\text { Model }\end{array}$ \\
\hline $\begin{array}{l}\text { Genital } \\
\text { Herpes }\end{array}$ & $\begin{array}{l}\text { Genital } \\
\text { Warts }\end{array}$ & Technology & $7.65 \mathrm{E}-11$ & Dependent & Disagrees & Agrees \\
\hline $\begin{array}{l}\text { Genital } \\
\text { Herpes }\end{array}$ & $\begin{array}{l}\text { Genital } \\
\text { Warts }\end{array}$ & HIV + Partner & $2.37 \mathrm{E}-11$ & Dependent & Disagrees & Agrees \\
\hline $\begin{array}{l}\text { Genital } \\
\text { Herpes }\end{array}$ & $\begin{array}{l}\text { Genital } \\
\text { Warts }\end{array}$ & $\begin{array}{l}\text { Sex } \\
\text { Orientation }\end{array}$ & $1.95 \mathrm{E}-11$ & Dependent & Disagrees & Agrees \\
\hline $\begin{array}{l}\text { Genital } \\
\text { Herpes }\end{array}$ & $\begin{array}{l}\text { Genital } \\
\text { Warts }\end{array}$ & Gender & $1.50 \mathrm{E}-11$ & Dependent & Disagrees & Agrees \\
\hline $\begin{array}{l}\text { Genital } \\
\text { Herpes }\end{array}$ & $\begin{array}{l}\text { Genital } \\
\text { Warts }\end{array}$ & Unprotected & $5.39 E-13$ & Dependent & Disagrees & Agrees \\
\hline $\begin{array}{l}\text { Sex } \\
\text { Orientation }\end{array}$ & Technology & Genital Herpes & $3.12 \mathrm{E}-10$ & Dependent & Agrees & Agrees \\
\hline $\begin{array}{l}\text { Sex } \\
\text { Orientation }\end{array}$ & Technology & Genital Warts & $5.43 \mathrm{E}-10$ & Dependent & Agrees & Agrees \\
\hline $\begin{array}{l}\text { Sex } \\
\text { Orientation }\end{array}$ & Technology & $\begin{array}{l}\text { \# Sexual } \\
\text { Partners }\end{array}$ & $1.12 \mathrm{E}-08$ & Dependent & Agrees & Agrees \\
\hline $\begin{array}{l}\text { Sex } \\
\text { Orientation }\end{array}$ & Technology & Unprotected & $6.62 \mathrm{E}-09$ & Dependent & Agrees & Agrees \\
\hline $\begin{array}{l}\text { Sex } \\
\text { Orientation }\end{array}$ & Technology & Syphilis & $5.10 \mathrm{E}-09$ & Dependent & Agrees & Agrees \\
\hline $\begin{array}{l}\text { Sex } \\
\text { Orientation }\end{array}$ & Technology & Gender & $1.89 \mathrm{E}-08$ & Dependent & Agrees & Agrees \\
\hline $\begin{array}{l}\text { Sex } \\
\text { Orientation }\end{array}$ & Technology & Race/Ethnicity & $9.23 \mathrm{E}-08$ & Dependent & Agrees & Agrees \\
\hline $\begin{array}{l}\text { Sex } \\
\text { Orientation }\end{array}$ & Technology & HIV + Partner & $8.45 E-08$ & Dependent & Agrees & Agrees \\
\hline
\end{tabular}




\begin{tabular}{|l|l|l|l|l|l|l|} 
Sex & & & \\
Orientation & Technology & Anonymous & $6.95 \mathrm{E}-08$ & Dependent & Agrees & Agrees \\
\hline
\end{tabular}




\section{Conclusions}

This dissertation sought to examine factors influencing the incidence of sexually transmitted disease (STD) among Florida Cohort Study participants living with HIV by examining their choice of venue to meet new sexual partners, participant demographics and, risky sexual behaviors.

Goal 1 of this dissertation was to examine characteristics by venue type. This study found more participants reported utilizing "technology \& in-person" methods to meet sexual partners than "technology-only" methods. Multivariate logistic regression found that participants who reported "technology-only" methods were 5.52 times more likely to be 25 - 29 years of age compared to individuals who reported using both "technology \& in-person" methods (i.e. utilized multiple venue types) (reference age group 30-39 years).

Goal 2 of this dissertation was to examine risky sexual behaviors and history of sexually transmitted disease by venue type. Findings indicated that "technology-only" participants were more likely to report more than five sexual partners in the prior 12 months and unprotected sex in the prior 12 months than "non-technology" participants (Table 2).

Goal 3 of this dissertation was to use Bayesian network analysis to identify a model which described the pathways between demographics, risky sexual behaviors, and sexually transmitted diseases by venue-type. Overall, the maximum likelihood model (banjo) was three times better than the model with significant (>1\%) likelihood (bnlearn). The banjo model suggests that technology usage directly influences number of sexual partners, reporting a history of STDs, having an HIV positive sexual partner, having unprotected sex, and having anonymous sex. 


\section{Implications}

Our findings, consistent with the current literature, suggest that differences in venue selection may vary depending on the demographics of the population. This study found that within this HIV positive cohort those who reported using "technology-only" methods were younger and those who reported using "in-person" only methods were older. Future studies should examine risky sexual behaviors and sexually transmitted diseases within this unique cohort population using this methodology of grouping by venue-type.

Prior to this study, whether reporting a recent STD and/or riskier sexual behaviors were more likely among those meeting new partners in technology-based venue types compared to non-technology-based venues were largely unknown, particularly within non-MSM populations. Individuals meeting new sexual partners using "Technology” are more likely to report unprotected sex in the prior 12 months and a history of syphilis than individuals utilizing "NonTechnology" methods; however, this did not remain statistically significant after controlling for other factors. Based on the findings of this study, STD history and sexual behaviors may vary depending on venue type for meeting sexual partners.

This study represents the first time learned Bayesian networks have been used in the context of data pertaining to the type of location where an individual meets sexual partners, risky sexual behaviors, and sexually transmitted diseases. Overall, the banjo model was three times better than the bnlearn model. The banjo model suggests that technology usage directly influences number of sexual partners, reporting a history of STDs, having an HIV positive sexual partner, having unprotected sex, and having anonymous sex. The model also suggests a pathway between these variables. The study concludes that learned Bayesian networks can be utilized in 
the context of examining the relationships between technology, demographics, risky sexual behaviors, and STDs.

\section{Limitations}

Significant limitation of this dissertation was the grouping of venue type due to small sample size by venues within the cohort. As such, further studies should seek to examine whether risks vary depending on specific venues vs. overall venue type. Another limitation of this study is that it is only representative of those living with HIV in Florida. Furthermore, similar studies should be conducted within a sample representative of a national population as popular venues may vary depending on the region of the United States. Lastly, a significant portion of the study participants were MSM. This limited our ability to examine specific characteristics associated with reporting a history of STDs among heterosexuals and women. However, future studies should specifically focus on recruiting these minority populations.

Scope

Overall, the conclusions of this dissertation fill gaps in knowledge concerning venue type selection among an HIV positive population. The findings also suggest possibilities for future studies delving deeper into the topics discussed. However, the authors conclude that technology does play a role in facilitating risky sexual behaviors and increasing the liklihood of an individual reporting a history of STDs - providing further evidence that PLWHAs may be swiping-right for an STD 


\section{VITA}

\section{ISABEL GRIFFIN}

Born, Parkersburg, West Virginia

2008-2012

B.A., Biology

Florida Atlantic University

Boca Raton, Florida

2012-2014

M.P.H

University of Miami

Miami, Florida

2015-2019

Doctoral Candidate

Florida Atlantic University

Miami, Florida

$2014-2019$

Outbreak Epidemiologist

Florida Department of Health in Miami-Dade County

Miami, Florida

Bioterrorism Epidemiologist

Florida Department of Health in Miami-Dade County

Miami, Florida

Virology/Bioterrorism Intern

Bureau of Public Health Laboratories

Miami, Florida

2019

Data Manager

Eagle Medical Services/CDC

Atlanta, Georgia

\section{PUBLICATIONS AND PRESENTATIONS}

Moore E., Rodriguez X., Fernandez D., et al. (2019). Zika Testing Behaviors and Risk Perceptions Among Pregnant Women in Miami-Dade County, One Year After Local Transmission. Maternal and Child Health Journal, 1140-1145.

Griffin I, et al. (2019). Zika virus specific immunoglobulin M antibody detection and neutralizing antibody profiles at 12 to 19 months after illness onset in confirmed cases. Emerging Infectious Disease, 25(2):299-303.

Griffin I, et al. (2018). Outbreak of Tattoo-Associated Nontuberculous Mycobacterial Skin Infections. Clinical Infectious Diseases, 949-955. 
Falise A, Griffin I, Fernandez D, et al. (2018) Carbon Monoxide Poisoning in Miami-Dade County following Hurricane Irma in 2017. Disaster Medicine and Public Health Preparedness, 13(1): 94-96.

Griffin I, et al. (2018). Examining the Role of Antioxidant Consumption and Active Tuberculosis. American Journal of Epidemiology, 187(7).

Griffin I, et al. (2018). Panic in a (Zika) Hot Zone. Journal of Epidemiology and Community Health.

Griffin I, et al. (2017). Epidemiology of Pediatric Zika Virus Infections. Pediatrics, 140(6): 20172044.

Likos A, Griffin I, Bingham AM, et al. (2016). Local Mosquito-Borne Transmission of Zika Virus -Miami-Dade and Broward Counties, Florida, June-August 2016. MMWR Morb Mortal Wkly Rep, 65:1032-1038.

Griffin I, Madhivanan P. (2016). A Systematic Review: Childhood Cancer Survivors and Gastrointestinal Cancer. Cancer Treatment Reviews, 55:209.

Bhoite P, Griffin I, Madhivanan P. (2016). Letter to the Editor-Robotic Assisted Hysterectomy in Obese Patients: A Systematic Review. Archives of Gynecology and Obstetrics (Springer), 294(2): 433-434. 